Revista de Derecho

de la Pontificia Universidad Católica de Valparaíso

XXXVI (Valparaíso, Chile, 2011, $1^{\text {er }}$ Semestre)

[pp. $531-573]$

\title{
La AdMinistración DE JUSTICIA COMO UN BIEN JURÍDICO
}

[“Administration of Justice as a Legally Protected Object”]

\author{
JAVIER WILENMANN* \\ Universidad Adolfo Ibáñez, Chile
}

\begin{abstract}
ReSUMEN
El artículo presenta una reconstrucción del objeto de protección en la categoría de los delitos contra la Administración de justicia. Para ello, en primer lugar se describe la prestación que realiza la Administración de justicia en una sociedad moderna. A partir de ello, el artículo critica distintas reconstrucciones de este bien jurídico, para finalmente dar cuenta de la idea que éste constituye una condición de posibilidad del ejercicio de la libertad, así como sus consecuencias.
\end{abstract}

Palabras Clave

Bien jurídico - Administración de justicia.

\begin{abstract}
This article addresses the reconstruction of the object of protection in the category of crimes against the Administration of justice. First, the provision made by the Administration of justice in a modern society is described. Based on this, this article criticizes several reconstructions of this legal right and finally explains that this constitutes a basic condition to exert freedom and its consequences.

\section{KEYWORDS}

Legal right - Administration of justice.
\end{abstract}

[RECIBIDo el 28 de octubre de 2010 y APROBADo el 28 de marzo de 2011].

* Profesor de Derecho en la Universidad Adolfo Ibáñez. Dirección postal: Diagonal Las Torres 2640, Peñalolén, Santiago, Chile. Correo electrónico: javier.wilenmann@ uai.cl. El autor agradece los comentarios hechos a un borrador preliminar por el profesor Juan Pablo Mañalich. 


\section{LA FUNCIÓN JUDICIAL Y EL BIEN JURÍDICO DE LA AdMINISTRACIÓN DE JUSTICIA}

El objeto del presente artículo es realizar una reconstrucción del objeto y del fundamento de protección de la categoría de delitos contra la Administración de justicia ${ }^{1}$.

$\mathrm{Al}$ igual que en todas las discusiones sobre la reconstrucción de un bien jurídico penal determinado, una labor de este tipo cumple al menos dos roles distintos: permite entregar un argumento a favor de una justificación de la existencia de una categoría de normas penales, esto es, constituye una postura en una discusión acerca de la legitimación sustantiva de la categoría; y, sobre todo, permite construir un criterio central de sistematización e interpretación de los tipos individuales que componen la categoría en cuestión ${ }^{2}$.

En el caso de la reconstrucción del bien jurídico de la Administración de justicia, el análisis correcto de las razones que dan cuenta de la necesidad de protección -su fundamento de protección-y la configuración que tiene en cuanto objeto de protección, requiere una exposición preliminar de presupuestos de la comprensión de ambas cosas. En primer lugar, el carácter lesivo de las conductas que típicamente se reconducen a la categoría en cuestión, para ser entendido con precisión, requiere poder comprender desde el punto de vista de la configuración de nuestra sociedad cuál es la importancia institucional de la actividad de los jueces, cuál es la forma de ejercicio correcto de su oficio, y de qué forma un ejercicio incorrecto de su función puede resultar dañoso social e individualmente.

A partir de ello, y dando cuenta de la función que el derecho cumple en la posibilitación del libre desarrollo de la personalidad al estructurar condiciones de coordinación de la acción, se sostendrá la tesis que el fundamento de protección de la Administración de justicia debe reconducirse a este carácter de condición de posibilidad que ella cumple. Ello, según se sosten-

\footnotetext{
${ }^{1}$ En lo que sigue, se utilizará la expresión administración de justicia, con mayúsculas, para designar al bien jurídico en cuestión. La expresión sin mayúscula designa al concepto tradicional, no penal, de administración de justicia, es decir, la actividad de los jueces o la función judicial.

${ }^{2}$ Ello produce una consecuencia peculiar en el contexto de la dogmática de la Parte especial. Como en cualquier rama del derecho, la interpretación dogmática y judicial dispone de tres tipos de argumentos interpretativos: lingüísticos, sistémicos y teleológicos o funcionales. La imposición de la sistematización a partir del concepto de bien jurídico produce como consecuencia analítica que los argumentos de tipo funcional (objetivo) tienden a coincidir con argumentos sistémicos. Ello refuerza el peso de la argumentación teleológica y, en parte, permite compensar la orientación a la argumentación formal impuesta por el principio central de la argumentación jurídico penal, a saber, el principio de legalidad.
} 
drá, permite al mismo tiempo reconocer que en tanto objeto de protección, la Administración de justicia se encuentra constituida por el conjunto de condiciones y deberes que requiere la administración de justicia para cumplir, en las condiciones contingentes de cumplimiento de la función del derecho, con la prestación que entrega a la sociedad. Las distintas sub-categorías de delitos contra la Administración de justicia atacan presupuestos distintos: así, por ejemplo, directamente el principio de sujeción al derecho en el caso de la prevaricación, o la necesidad de confianza en las declaraciones y otras pruebas presentadas en el proceso, en tanto contexto especialmente protegido respecto de representaciones falsas dada la fragilidad de la posición cognitiva de los jueces, en el caso de delitos de falso testimonio y otras falsedades en el proceso.

\section{LA FUNCIÓN DEL DERECHO Y LA FUNCIÓN JUDICIAL}

\section{Vinculo conceptual e histórico entre función del Derecho y función ju- dicial.}

La prestación que cumple la actividad judicial, desde el punto de vista de la configuración de la sociedad, coincide, al menos parcialmente, con la función que asignamos al Derecho. La actividad judicial se define precisamente en relación con el Derecho: si, como en la modernidad, es posible distinguir legislación y jurisdicción, esta última no es sino la actividad que tiene por objeto aplicar el Derecho3.

Al parecer no ser más que la manifestación institucional visible de la idea

${ }^{3}$ Desde Kelsen es, por cierto, problemática la distinción fuerte entre producción y aplicación del Derecho. Según Kelsen, todo acto de una cadena de validez es, lógicamente, producción y aplicación del derecho, a excepción de ambos extremos, de los que no forma parte ni la producción típica de éste (la ley), ni la aplicación típica de éste (la sentencia judicial). Sobre lo anterior, véase: KeLsen, Hans, Teoría pura del Derecho (México D.F., Universidad Nacional Autónoma de México, 1979), pp. 246 ss. Por la razón anterior, suele discutirse la idea de que la función judicial sea simplemente la aplicación de la ley. En todo caso una cuestión es evidente: la crítica de Kelsen no funciona en el mismo plano que la distinción reseñada. La distinción entre creación $\mathrm{y}$ aplicación como correlato de la distinción entre legislación y jurisdicción no es una distinción pura de lógica normativa, como lo pretende Kelsen, sino una distinción de alcance (alcance normativo general vs. alcance normativo particular), de justificación argumentativa (justificación normativamente innecesaria para la validez de la norma vs. justificación como fuente de la validez de la decisión judicial) y una distinción política (creación como lo propio de la legislación, políticamente legitimada vs. aplicación como lo propio de la jurisdicción, sin legitimación política salvo en su vínculo institucional y profesional con la ley). El propio Kelsen reconoce, aunque los presenta como diferencias de grado, las dos primeras distinciones relativas a la aplicación y creación de derecho. 
puramente normativa de Derecho, la administración de justicia manifiesta una dependencia conceptual respecto de éste. Aún en su comprensión más simple, la administración de justicia es dependiente de la concepción del Derecho no sólo por tratarse de la encargada de su aplicación, sino que además porque se encuentra configurada por éste y creada por éste. Por ello función del Derecho y función de la administración de justicia tienen necesariamente un campo de coincidencia, al menos, parcial.

La dependencia entre administración de justicia y Derecho no es puramente unilateral, lo que manifiesta con aún mayor fuerza la casi-coincidencia necesaria como categoría funcional que existe entre Derecho y administración de justicia. La administración de justicia, incluso entendida simplemente como órgano, es un presupuesto necesario de la idea de Derecho, ya que permite su exigibilidad coactiva y su funcionamiento en condiciones de relativa certeza ${ }^{4}$. En ese sentido, y pese a que parezca intuitivamente que se trata de dos conceptos fácilmente discernibles, Derecho y administración de justicia manifiestan una dependencia recíproca tan fuerte que puede hacer parecer ilusoria la distinción entre ambos. Tanto el normativismo radical como el realismo radical, de hecho, defienden su confusión ${ }^{5}$.

Por lo mismo, la función de la administración de justicia reproduce, al menos, una parte de la función del Derecho. Ya en la construcción de la idea misma de una función estatal específicamente aplicadora de Derecho, se manifiesta conceptualmente el vínculo de la función de lo que debe ser aplicado, con la prestación que se entrega al aplicarlo. Este vínculo conceptual se manifiesta, asimismo, en tradiciones jurídicas determinadas y en la historia de las instituciones. Así lo hace históricamente de forma particularmente clara en la Ilustración. A la concepción continental de la Ilustración de la función del Derecho como coacción necesaria para la compatibilidad y el ejercicio de la libertad determinado precisamente por quienes ven afectada su libertad ${ }^{6}$,

${ }^{4}$ Cfr. Habermas, Jürgen, Facticidad y validez (4a edición, Madrid, Trotta, 2005), pp. 200 ss.

${ }^{5}$ Como se verá más adelante, en materia de bien jurídico manifestar una confusión entre ambos, y constituir a los delitos contra la administración de justicia en delitos contra el Derecho conduce a una dificultad importante. Ello lleva necesariamente a tener que, o bien, distinguir entre administración de justicia, como bien jurídico, y administración de justicia, como concepto autónomo, o bien tener que defender la diferencia conceptual entre Derecho y administración de justicia. Pese a que del trabajo puede deducirse, correctamente, que presupone una distinción como la segunda, hacer el trabajo argumentativo correspondiente excede el interés y las posibilidades del presente artículo. Por ello debe asumirse que, al menos, hay una distinción necesaria entre "administración de justicia" -concepto penal-y "administración de justicia” -concepto de teoría del Derecho.

${ }^{6}$ Montes $u i e u$, De l'esprit des lois (Paris, Gallimard, 1995), pp. 327 ss. En mate- 
subyace la idea de la separación de poderes y del ejercicio independiente pero vinculado a la ley de la función judicial, como una condición necesaria del cumplimiento de la función del Derecho. Esta forma de estructuración institucional de la administración de justicia, que puede parecer intuitiva en la actualidad, sólo es conceptualmente necesaria bajo esa construcción del Derecho y, de hecho, fue este cambio en la comprensión de su función el que llevó a una estructuración institucional de este tipo. Como presupuesto de aplicación, la separación de poderes sólo es contingentemente necesaria para permitir la libertad de los ciudadanos, e incluso puede ser contraproducente al establecimiento de un Estado externamente poderoso o para llevar a cabo cambios sociales radicales 7 . En su exposición, Montesquieu es sumamente claro al vincular la separación de poderes al objetivo específico de permitir el ejercicio de libertades, utilizando reiteradamente expresiones como "il n'y a point de libertê" 8 cuando se reúnen dos o más poderes. La separación de poderes como condición esencial del ejercicio de la actividad judicial no tiene una explicación funcional para la maximización de la eficacia del poder, sino una justificación relativa a la libertad de los ciudadanos, y por ello nace con la identificación de una función liberal del Derecho.

La ideología de la Revolución Francesa, y la institucionalización de ésta, marcaron de forma aún más directa esta relación. Conforme a ésta, el Derecho no sólo sería una condición para el ejercicio de la libertad, necesario para articular el posible conflicto de varias libertades en juego, sino que además el Derecho sería directamente una manifestación de la libertad de

ria penal ello corresponde a la fundamentación de Feuerbach de la pena, inspirada en la filosofía kantiana del derecho. A su vez, la concepción kantiana del derecho es central en la comprensión de las relaciones entre derecho, libertad y moralidad en la filosofía ilustrada. Sobre ello, véase: KANT, Immanuel, La metafisica de las costumbres (Madrid, Tecnos, 2002). Respecto de la conexión con Feuerbach, Jakoвs, Günther, La pena estatal: significado y finalidad, en EL MISMO, El fundamento del sistema jurídico penal (Lima, ARA Editores, 2005), pp. 32 ss.

${ }^{7}$ Esto se encuentra en la base de la crítica de Schmitt a la supuesta preponderancia puramente teórica de una concepción parlamentaria del Estado a través del concepto de voluntad general. Según Schmitt, el parlamentarismo jurídico constituye antes una solución de compromiso, adaptada a necesidades políticas contingentes, frente a la posibilidad de estructurar el derecho de forma puramente conservadora (Estado jurisdiccional, en el que los tribunales defienden el statu quo de lo justo) o de forma radicalmente rupturista (Estado gubernativo, en el que el poder central tiene mayores facultades de llevar a cabo cambios relevantes). Cfr. Sснмітт, Carl, Legalidad y legitimidad (Granada, Comares, Colección Crítica del Derecho, 2006), pp. 1 a 8.

${ }^{8}$ Montes tal vez, simplemente "No hay libertad". Pero la formula que elige Montesquieu tiene por objeto reforzar la idea de lo que falta, por sobre la negación simple "il n'y a pas de liberte". 
los ciudadanos?. Por ello, la administración de justicia no sólo tendría que configurarse como poder independiente, sino que además ésta agotaría sus posibilidades de actuación en la aplicación puramente mecánica de la ley: sólo ella podría ser considerada coacción originada en la voluntad del propio sujeto coaccionado. Cualquier forma de creación o de discreción de los jueces sería manifestación de la voluntad de éste y no, en cambio, de la voluntad general, expresión de la libre determinación ciudadana en la interpretación formalista de Rousseau. Ello la haría injustificable ${ }^{10}$. El rechazo a la discrecionalidad y a la concesión de facultades creativas al juez dio lugar durante la Primera República a la instauración de un sistema institucional en el que en cualquier caso difícil, en que la ley no resultara claramente aplicable o existiera un conflicto de normas, el juez debía dirigirse a la Asamblea Legislativa, representante formal del pueblo, para que ésta se manifestara respecto de la verdadera interpretación de la ley en cuestión, o solucionara eventuales vacíos legales ${ }^{11}$. Este es probablemente el ejemplo más fuerte de la construcción de un vínculo claro entre la concepción de la función del Derecho y la configuración de la actividad judicial, así como de la influencia directa que la concepción que se tenga de la función del derecho tiene sobre los deberes y prohibiciones de la administración de justicia.

Pese a la superación, dada sus propias imposibilidades y producto del desarrollo de la teoría de la argumentación jurídica, de la posibilidad de un positivismo puramente legalista, la justificación liberal del Derecho sigue siendo, en una sociedad republicana y democrática, la forma más verosímil de reconstruir la función de éste, sobre todo a la luz del mantenimiento de una

\footnotetext{
${ }^{9}$ Rousseau, Jean Jacques, El contrato social y otras obras (Buenos Aires, Losada, 2003), pp. 67 a 77; GARCÍA DE ENTERRÍA, Eduardo, La democracia y el lugar de la ley (Madrid, Civitas, s.d.), pp. 29 ss. .

${ }^{10}$ García DE EnTERRÍA, cit. (n. 9), pp. 38-41. En materia penal, particularmente relevante desde un punto de vista histórico: BECCARIA, César, De los delitos y las penas (México D.F., Fondo de Cultura Económica, 2000), p. 220.

${ }^{11}$ Sobre el "référé législatif”, véase: García DE EnTERría, cit. (n. 9). Más allá de sus problemas prácticos y de la deformación de la distinción entre razonamiento universal centrado en la legislación y razonamiento particular centrado en el juez, la referencia legislativa descansaba sobre un presupuesto errado. Su fundamento se basaba en la idea que permitía conciliar un caso sin voluntad universal con la voluntad universal a través de una manifestación concreta de ésta, de forma tal de respetar el derecho del individuo a no ser sometido a coacción externa. Pero este fundamento se desentiende de la dimensión de legitimación temporal (base de las prohibiciones de retroactividad) que subyace al problema de la autonomía. No se trata sólo que el sujeto haya prestado formalmente su consentimiento a la aplicación de la coacción por la infracción de la norma, sino que lo haya hecho antes de infringir la norma. Si la norma aparece como expresión universal de la voluntad de forma retroactiva, es indudable que hay imposición de una voluntad (ahora colectiva) heterónoma al sujeto coaccionado.
} 
configuración institucional parcialmente vinculada a la concepción ilustrada, en virtud de la cual el postulado de que la administración de justicia tiene por objeto posibilitar el libre desenvolvimiento de la personalidad sigue siendo su mejor justificación.

Sin embargo, desde el punto de vista de la configuración liberal del Derecho penal, entender que la posibilitación del ejercicio de la libertad es el objeto de protección de una clase de delitos determinada, es una respuesta demasiado vaga e imprecisa como para ser aceptable. La justificación liberal del Derecho penal derivada de la Ilustración precisamente constituye a todos sus bienes jurídicos, en algún nivel, en objetos de protección del libre desenvolvimiento de la personalidad ${ }^{12}$. Convertir a los delitos contra la Administración de justicia en una especie de meta-categoría que protege todos los otros bienes jurídicos y a la libertad general de acción, no sólo daría lugar a una construcción poco interesante por no tener posibilidad de aplicación alguna, tal como lo sería constituir a los delitos contra la libertad en una categoría omnicomprensiva o subsidiaria ${ }^{13}$, sino que además sería sumamente inverosímil dada la especificidad de los delitos contra la administración de justicia.

\section{La función de la administración de justicia en la Sociología.}

Para entender en qué nivel la función judicial incide sobre la libertad general, y, a partir de ello, qué presupuestos se requieren para que la administración de justicia cumpla con su función, la Sociología y la Filosofía política entregan instrumentos más precisos de análisis. A la respuesta, que para estos efectos es tautológica, respecto a que la función del derecho es, a partir de un mínimo de coacción necesaria, permitir el ejercicio de la libertad, la sociología ha precisado en qué sentido el Derecho, y por lo tanto la actividad de los jueces, es necesaria al funcionamiento de una sociedad moderna que le reconoce capacidad de decisión y acción libre al individuo. En el análisis de la función del derecho, así como del lenguaje normativo en general ${ }^{14}$, casi

\footnotetext{
${ }^{12}$ Esta consideración es la que constituye la dificultad en la demarcación de la libertad como objeto general de protección y la libertad como bien jurídico especial, ya que "estrictamente considerado, todo delito es un delito contra la libertad", TitTmanN, Karl August, Contribuciones a la doctrina de los delitos contra la libertad (Meißen, 1806) (traducción de Bascuñán Rodríguez, Antonio); véase también: Carrara, Francesco, Programa de Derecho criminal (Bogotá, Editorial Temis, 1958), II, pp. 323 ss. .

${ }^{13}$ Sobre el particular, véase: BAscuñán RodrígueZ, Antonio, La regulación española de la coerción en el marco de la codificación europea (Madrid, ADPCP, 1994), pp. 266 ss. .

${ }^{14}$ El vínculo evidente que en una reconstrucción parcialmente pragmática de la moral, como la ética del discurso, tiene el lenguaje moral con el problema de las expectativas de acciones y la coordinación de acciones, puede verse por ejemplo en HABERMAS,
} 
toda la herencia de la tradición sociológica iniciada con Weber se centra en el problema de la coordinación de acciones y de la inserción del comportamiento en un contexto de expectativas de comportamiento de los otros.

El problema inicial, con el que se inicia el análisis weberiano, es simple de entender. En la representación de Weber, si se le concede a cada individuo la posibilidad de definir libremente sus intereses, y así trazar libremente un plan de acción, de la multitud de planes de acción que puedan trazarse para perseguir intereses congruentes, excluyentes o contradictorios con los de los otros con quienes se tienen contactos anónimos, necesariamente surgirían conflictos voluntarios e involuntarios entre los agentes a quienes, teóricamente, se les habría otorgado la posibilidad de conseguir la satisfacción de esos intereses mediante sus planes de acción ${ }^{15}$. Esto es, si en una sociedad moderna la acción no tiene un marco de orientación para los agentes, la posibilidad del ejercicio de la libertad daría lugar a una serie de situaciones de conflicto y, al extremo, a una situación de conflicto permanente.

Ni siquiera presuponiendo racionalidad finalista sofisticada de todos los agentes y conocimiento de los intereses de los otros -lo que además se ve limitado por el relativo anonimato del intercambio-, podría evitarse esta situación de conflicto, porque pese a que un agente puede en esas condiciones prever formas de acción que eviten conflictos con quienes tengan intereses cercanos, para así satisfacerlos de mejor forma, la posibilidad que también el otro anticipe esta situación daría lugar a comportamientos estratégicos de parte de ambos que finalmente llevarían de vuelta a lo impredecible y al conflicto. Los comportamientos se volverían impredecibles aún con conocimiento perfecto, y ello imposibilitaría la libertad de acción ${ }^{16}$. Por ello, para permitir efectivamente la coordinación de la acción, resultaría necesario un marco de orientación de ésta que posibilite un contexto de coordinación de acciones. Este contexto de coordinación tiene que venir dado por prestaciones que permitan estabilizar el comportamiento social, es decir, que permitan que sus agentes anticipen con base cognitiva suficiente el comportamiento de otros. En el desarrollo de la sociología, Weber con-

Jürgen, Teorias de la verdad, en EL Mismo, Teoría de la acción comunicativa: complementos y estudios previos (Madrid, Cátedra, 1989), p. 93 ; Habermas, Jürgen, Objeciones de Hegel contra Kant y la ética del discurso, en El mismo, Aclaraciones a la ética del discurso (Madrid, Trotta, 2000), pp. 18 - 22. Para una explicación más detallada sobre las distintas pretensiones de una teoría moral y el lugar de la ética del discurso, véase: Habermas, Jürgen, Sobre el uso pragmático, ético y moral de la razón práctica, en del mismo, Aclaraciones a la ética del discurso (Madrid, Trotta, 2000), pp. 109 ss.

${ }^{15}$ Weber, Max, Economía y Sociedad (2a edición, México D.F., Fondo de Cultura Económica, 1969), pp. 21 ss. .

${ }^{16}$ Cfr. Luhmann, Niklas, Sistemas sociales. Lineamientos para una teoria general (México D.F., Anthropos Editorial, 1998), pp. 113-115. 
ceptualizó el marco de coordinación en la idea de la formación de valores, o de órdenes, institucionalizados. Por su parte el funcionalismo de Parsons y posteriormente Luhmann lo ha desarrollado conceptualmente a partir del concepto de expectativas normativas. En ambos casos, con diferencias conceptuales relevantes, se considera que el Derecho, la coacción que constituye al Derecho, permite la formación de este contexto necesario para la coordinación de la acción ${ }^{17}$.

El análisis de Weber, a partir de la categoría básica de la acción, es central en el desarrollo de la explicación sociológica de la función del Derecho. La sociedad necesitaría, para permitir la coordinación de la acción de sus individuos, la existencia de lo que Weber denomina un "orden legítimo"18. Es decir, la posibilidad de anticipar formas de acción del otro con base cognitiva de no defraudación suficiente en contextos de interacción determinados que permita desarrollar la acción racional, tendría que tener lugar por algo más que la mera repetición empírica anterior de acciones similares. La acción propia, que se orienta hacia un objetivo suponiendo formas de acción del otro, sería mucho más eficiente si además esa forma de acción pudiera ser explicada a partir de valores compartidos, siendo así reconocida como válida también por los otros. Esto es, si todos los agentes reconocieran validez en las acciones de los otros agentes, y por lo tanto anticipabilidad justificada, la acción podría coordinarse con relativa eficacia. La justificación de la acción en ese contexto particular de validación tendría un poder de aceptación, y por lo tanto de coordinación, mucho más fuerte que la mera acción explicada estratégicamente sin más, con lo que los intereses del agente podrían satisfacerse con una probabilidad cognitiva mucho mayor. Ese otorgamiento compartido de validez, de corrección, a ciertas formas de acción sería posible a partir de la imagen de legitimidad que expone la mera legalidad en las sociedades modernas ${ }^{19}$, las que en general sujetan la determinación de la validez de las normas al puro cumplimiento de condiciones formales de validación. Pero además el Derecho otorgaría garantías para el cumplimiento de esas formas de acción mediante la posibilidad del uso de la coacción. Por ello, la eficacia integrativa del Derecho se debería a la combinación de su dimensión de legitimidad externa y formal con su dimensión coactiva.

Por cierto, la legalidad no sería la única forma posible de dominación e integración a partir de la legitimidad, ni tampoco necesariamente la forma más eficaz, pero sí se trataría de la forma de legitimación de intereses y coor-

\footnotetext{
${ }^{17}$ Habermas, cit. (n. 4), pp. 131 a 133.

${ }^{18} \mathrm{El}$ concepto de orden legítimo es central en la explicación de Weber. Cfr. WEBER, cit. (n. 15), p. 25.

${ }^{19}$ Ibíd. Ver también Habermas, cit. (n. 4), pp. 132 y 133.
} 
dinación de acciones más expandida en las sociedades modernas, y de forma contingente de la más eficiente ${ }^{20}$.

Si bien es cierto que en Weber el análisis del derecho explícitamente no puede reducirse a lo que éste denomina su aspecto "sociológico" o "empírico" 21 , desde el punto de vista de la función del derecho éste es su aspecto central en su teoría. Dentro de esta exposición, el derecho no sería más que una parte de un proceso de racionalización propio de la cultura occidental. En sus escritos fundamentales, Weber se centra principalmente, además de su comprensión de la sociología de la religión ${ }^{22}$, en la racionalización de la economía capitalista y del Estado burgués, y precisamente en la racionalización del derecho privado de forma de permitir la obtención calculada de satisfacción de intereses personales conforme a su modelo de racionalidad final ${ }^{23}$.

En el caso del funcionalismo, pese a tener diferencias conceptuales relevantes, sus conclusiones en materia de función del derecho no son radicalmente distintas. El punto de partida metodológico del análisis del funcionalismo se encuentra en la elección del concepto "sistema" como punto central de desarrollo de su teoría sociológica ${ }^{24}$, por oposición a la unidad elemental de "acción” de la sociología weberiana. Los sistemas constituirían formas de relación de elementos condicionados por su propia reglamentación, cerrados parcialmente a su entorno y cerrados igualmente a otros sistemas en su entorno. Sin embargo, las relaciones entre elementos en el sistema no agotarían las posibles relaciones que la teoría de sistemas les atribuye, puesto que pese a que tengan ciertas formas de cierre, los sistemas y subsistemas sociales mantendrían relaciones con sistemas en su entorno e incluso con el entorno mismo ${ }^{25}$.

El punto central de la teoría de sistemas en la explicación del derecho es la comprensión de la organización interna y del funcionamiento de sistemas casi herméticos. Esta elección metodológica le permite al funcionalismo reconstruir los intercambios sociales de forma distinta a la construcción de Weber a partir de la unidad elemental de "acción”, no ya centrado en la

${ }^{20}$ Ibíd., p. 30.

${ }^{21}$ WeBER, cit. (n. 15), p. 251.

${ }^{22}$ Cfr. Weber, Max, La ética protestante y el espiritu del capitalismo, en El MISMo, Obras selectas (Buenos Aires, Distal, 2003), pp. 17 ss. .

${ }^{23}$ Para una crítica completa, véase, por ejemplo: Habermas, Jürgen, Aspectos de la racionalidad de la Acción, en del mismo Teoría de la acción comunicativa: complementos y estudios previos (Madrid, Cátedra, 2001), pp. 372 ss. .

${ }^{24}$ LuhmanN, cit. (n. 16), pp. 27 ss. .

${ }^{25}$ Ibíd. p. 53. 
subjetividad actual o ideal de los agentes, sino en sus relaciones funcionales y en su organización como un todo, esto es, como un sistema.

Tratándose de sistemas sociales, la formación de éstos a partir de la comunicación que se desarrolla en ellos es posible y se hace necesaria precisamente a partir del problema de la doble contingencia. El funcionalismo sostiene que no es sólo que los problemas de coordinación sean solucionados por la formación de marcos de orientación, como en Weber, sino que el problema de la coordinación de la acción, por la necesidad de ser resuelto, se encontraría en el origen mismo de la formación de los sistemas sociales ${ }^{26}$. Dicho de otra forma: no sólo la estructuración social racional sería una respuesta a la doble contingencia, sino que la doble contingencia forzaría a la organización racional de la sociedad.

Pero aun cuando la sociedad se constituya sobre el conflicto, ésta no pretendería ni podría excluirlo ni fáctica ni normativamente. Esto puede parecer contra-intuitivo por el grado de afectación que supone el conflicto al sistema: el sistema social asume condiciones particularmente lesivas de su identidad como posibles. A diferencia de los sistemas psíquicos, los sistemas sociales sólo forman unidad por medio de la comunicación, por lo que el conflicto entre sus elementos, o con sus elementos, afecta la identidad del sistema social y, por lo tanto, al sistema mismo. Esta unidad sistémica, constituida necesariamente de forma inestable de forma de permitir el cambio al interior del sistema ${ }^{27}$, al aceptar su propia inestabilidad aceptando el conflicto crearía un riesgo de erosión de su identidad comunicativa. Con ello, el sistema social tendería a crear un subsistema encargado de disponerlo a la inmunidad pese a la existencia de conflictos, de forma de permitir mantener identidad comunicativa aún aceptando la contestación comunicativa de la identidad. Esto es lo propio de sociedades modernas.

La función del Derecho se hace comprensible en este contexto. En la concepción funcionalista, el Derecho tiene por función esencial mantener la identidad comunicativa de la sociedad. El Derecho se anticiparía y reaccionaría frente a conflictos que puedan afectar de modo más o menos fuerte la identidad de la sociedad de forma de mantener su capacidad autoreproductiva. Esto no significa que el Derecho tenga por pretensión negar la posibilidad de cualquier cambio de identidad al interior de la sociedad. El Derecho, a su vez, actúa como mecanismo que a partir del conflicto posibilita el cambio regenerativo institucional de la identidad comunicativa del sistema social. Esto es, en la determinación de lo justo o injusto, la aplicación del Derecho no sólo mantiene expectativas normativas de conducta, y con ello la identidad del

\footnotetext{
${ }^{26}$ Ibíd., pp. 114, 131.

${ }^{27}$ Ibíd. p. 332.
} 
sistema social, sino que también permite la generación de otras expectativas de conducta ${ }^{28}$. La función del Derecho discurre entre la mantención de las expectativas de conducta al interior del sistema social y en su cambio, pero en cualquier caso es condición de posibilidad, en sociedades modernas, de la estabilización de éstas y de su conformación como un sistema que acepta el conflicto pese a que éste pueda erosionar su identidad misma.

\section{La pretensión interna de la aplicación del Derecho.}

Un análisis externo como el sugerido, sin embargo, esconde la pretensión directa de la resolución del conflicto en el caso particular. Si bien efectivamente la aceptación del conflicto en la sociedad, así como el problema de la doble contingencia, requieren de un marco estabilizador que funcionalmente lo otorga el Derecho, en la aplicación de éste la pretensión central del juez no es una pretensión puramente funcional, sino una pretensión particular de corrección. El derecho no es sólo una forma de acción interesada, sino que precisamente lo que explica su eficacia es que constituye un saber cultural asimilable, en un plano específico, a la moral entendida de forma cognitivista - racionalista, es decir, se trata en la posición del juez de un saber al menos pretendidamente des-interesado. La posibilidad de asumir lo que constituye en Hart el aspecto interno del derecho ${ }^{29}$, y la necesidad de que así lo hagan quienes se encuentran a cargo de su aplicación ${ }^{30}$, constituyen un segundo plano de la función del Derecho que a la vez se opone y complementa su función externa, y que es central en la comprensión de la actividad judicial. La aplicación del Derecho se mira a sí misma como la solución correcta normativamente de un conflicto, y en principio no sólo como excusa para constituir o estabilizar expectativas normativas que parecen funcionales a los intereses del Estado o de la comunidad.

Ambos niveles son necesarios para entender la prestación total que le otorga la administración de justicia a la sociedad, y explican la forma en que ésta se encuentra configurada. Por ello, permiten ver las razones del castigo del incumplimiento de las obligaciones que se les imponen a los funcionarios o incluso a los particulares en relación con esta prestación.

${ }^{28}$ Ibíd. p. 337 y 338.

${ }^{29}$ Hart, H.L.A., El concepto del Derecho (Buenos Aires, Abeledo Perrot, 1977), pp. 104 ss. .

${ }^{30}$ Ibíd., p. 144-146. Asimismo, para una explicación racional de esta ceguera funcional: Rawls, John, Dos conceptos de reglas, en Teorias sobre la Ética (México D.F., Fondo de Cultura Económica, 1974), pp. 210 ss. 


\section{Presupuestos De la CONFiguración}

DE LA FUNCIÓN JUDICIAL

La función de la administración de justicia puede ser descompuesta en al menos dos aspectos, y cumple con otras funciones marginales, contingentes, y más conflictivas. En este apartado se analizarán brevemente estos aspectos, mostrando de qué forma influyen sobre los presupuestos generales de la configuración de la función judicial. Posteriormente se analizarán derechamente estos presupuestos, configurados como principios.

\section{La relación entre la función de la administración de justicia y su confi- guración.}

La estabilización de expectativas normativas, o en general la formación de un marco que permita el libre desenvolvimiento de la personalidad, es la función externa de la administración de justicia. Ésta, al cumplir con esa función, debe estabilizar, e institucionalizar el cambio, de las expectativas que ha constituido, de diversas formas, la sociedad en cuestión. Así como un Parlamento constituye expectativas normativas que sean representativas de la sociedad, determinando formas correctas e incorrectas de acción, la administración de justicia debe estabilizar expectativas normativas y confirmar normas que igualmente representen la identidad de la sociedad, lo que requiere de procedimientos mucho más complejos que los puros procedimientos formales de la formación de normas legales propios de la legislación en sentido estricto. Mientras la representatividad de las leyes, y por lo tanto de la forma primaria de constitución de expectativas normativas, se asegura procedimentalmente por medio de la elección pública de quienes ejercen la función legislativa, la representatividad de su estabilización por medio de la aplicación se asegura de forma mucho más compleja, e inestable, en lo que de forma simple puede denominarse el mandato de sujeción al Derecho. Esto es, a la cuestión puramente procedimental de la legislación se opone la identidad argumentativa de la jurisdicción. Sobre ello volveremos más adelante.

El que el proceso de estabilización de expectativas normativas en las sociedades modernas deba ser un procedimiento de autocomprensión de la sociedad en cuestión, influye en al menos dos aspectos centrales que pasan a ser necesarios a la función judicial. El primero es, desde un punto de vista procedimental, el ya reseñado mandato de sujeción al Derecho. Desde un punto de vista organizativo, a su vez, la separación de poderes es, parcialmente, una consecuencia de la necesidad de que la estabilización de expectativas normativas sea representativa.

El vínculo entre separación de poderes y representatividad, menos obvio que el vínculo entre representatividad y sujeción al derecho, requiere de una 
explicación adicional. Una explicación a este vínculo lo ofrece, por ejemplo, Habermas. De acuerdo a la tesis de Habermas, en las sociedades humanas no primitivas, el poder político institucionalizado y el Derecho se constituirían y posibilitarían recíprocamente. Mientras el Derecho le entregaría al poder institucionalizado la apariencia de legitimidad que éste necesitaría, el poder, entendido como violencia legítima y teóricamente irresistible, le permitiría cumplir con sus funciones ${ }^{31}$. Ello haría lógicamente posible, y en los hechos probable, que el poder llegue, de hecho, a instrumentalizar estratégicamente al Derecho. Es decir, la representatividad del Derecho se encuentra condicionada por la posible instrumentalización del Derecho por el poder institucionalizado e incluso por quienes aspiran al poder. Sin separación de poderes, el creador y aplicador del Derecho puede simplemente valerse de la apariencia de legitimidad del Derecho para maximizar su poder, sin pretender cumplir con la función del Derecho. De hecho, incluso la dominación política puramente vertical, no representativa, también podría constituir y estabilizar expectativas normativas. Por lo anterior, la separación de poderes no es un presupuesto de la posibilidad de estabilizar expectativas normativas en abstracto, ni es un presupuesto necesario de la posibilidad de una cierta coordinación de la acción. La separación de poderes, en cambio, fuerza una organización que permite que el poder se sujete al Derecho legítimo, al derecho representativo. La separación de poderes tiende a impedir la instrumentalización del Derecho por el poder, y por lo mismo tiende a que las expectativas normativas que se estabilizan sean representativas de la voluntad de la comunidad, no sólo permitiendo, por lo tanto, una cierta coordinación de la acción, sino permitiendo que esa coordinación de la acción sea manifestación de la auto-determinación de la comunidad y, por ello, de su libertad ${ }^{32}$. El vínculo entre representatividad y separación de poderes se manifiesta, por lo tanto, en que el segundo es una condición institucional (contingente) de posibilidad del primero.

Por otro lado, en la resolución de conflictos necesariamente debe expresarse una norma jurídica que tiene una particular pretensión de corrección.

\footnotetext{
${ }^{31}$ Sobre las relaciones entre poder y derecho, en detalle Habermas, cit. (n. 4), p. 212 ss. .

${ }^{32}$ En todo, Habermas, Ibíd., pp. 237 ss. , y 256-258. Para un análisis diacrónico de la evolución de esta relación, véase: también Habermas, Jürgen, ¿Cómo es posible la legitimidad por vía de la legalidad? en Doxa, 5 (1988), pp. 21 a 45. Por cierto, esta no es la única justificación de la separación de poderes. La división de función legislativa y adjudicadora se explica, también, por los distintos tipos de argumentación que lógicamente se desarrollan en la fundamentación y aplicación de normas, pese a que la distinción no sea del todo análoga a la distinción estándar entre creación de normas generales y aplicación de éstas. Al respecto véase: la nota número 2.
} 
Mientras al tratar su función externa se asume completamente un análisis puramente objetivante, centrado en su aspecto externo, la otra forma de mirar la función judicial asume completamente la perspectiva del participe. Desde el punto de vista del juez, su función tiene que ser exclusivamente resolver conforme a derecho el caso, esto es, expresar lo que es correcto desde la perspectiva del Derecho en una situación individual determinada a partir de normas relativamente indeterminadas ${ }^{33}$. Esto lo reconoce incluso positivamente el derecho chileno, que caracteriza exclusivamente a los jueces en relación con esta función en el artículo 1 del Código Orgánico de Tribunales, y en el artículo 76 de la Constitución Política de la República. Si bien, esta necesidad ya se explica parcialmente por la necesidad de que las expectativas que se estabilizan representen las expectativas que constituye el poder comunicativo, ambas cosas se encuentran y tienen que encontrarse fuera de la perspectiva directa del juez. Al momento de la resolución del conflicto, el juez no piensa, o no debe pensar, directamente que fallar de una u otra forma sirva a estabilizar expectativas determinadas que serían mejores para las relaciones interpersonales generales en el marco de una sociedad compleja, ni mucho menos en intereses particulares. El juez reconstruye el caso a partir de otros códigos, como "justo" o "injusto", o señala que una parte tiene un "derecho" o una "obligación", y que por lo mismo tiene que reconocer la pretensión de la parte que actuó correctamente o que tiene una pretensión legítima o, lo que es lo mismo, conforme a derecho. Esto es, desde la perspectiva del juez, su función es determinar lo que conforme a reglas del sistema es correcto en ese caso, y así terminar definitivamente con el conflicto. Que, desde el punto de vista de la sociedad, ello resulte en la estabilización de expectativas normativas contrarias a las creencias personales del juez sobre la mejor configuración posible de la libertad general de acción

${ }^{33}$ En la filosofía idealista, Hegel demuestra que el único objetivo del juez es "el conocimiento y la realización” de lo universal (en un sentido particular, el derecho y la ley) sobre "el querer particular", con independencia de cualquier interés particular. La función del juez, sus limitaciones, no se justifican por cuestiones externas como en el primer aspecto reseñado en esta exposición, sino por respeto a que el ejercicio del derecho sea, o pueda ser, reflejo de la autoconciencia que debieran tener las partes. Sobre ello, Hegel, G.W.F., Principios de la Filosofía del Derecho (Buenos Aires, Editorial Sudamericana, 2004), p. 207. 
debe serle irrelevante ${ }^{34} 35$.

Por cierto al no constituir el aspecto interno más que la contra-cara de su función analizada desde un punto de vista externo, los presupuestos de la administración de justicia en relación con este aspecto son similares. El mandato de sujeción al Derecho es evidentemente la expresión directa de la función del derecho vista desde el punto de vista interno. Asimismo, la imparcialidad y la independencia del juzgador son esenciales para que el ejercicio de la función no sea simplemente funcional al poder, sino que sea exclusivamente resolver el caso que se le presenta con la particular pretensión de corrección que tiene la sentencia judicial.

\section{Principios de configuración de la administración de justicia.}

Los principios de la organización de la administración de justicia responden a las preguntas sobre las condiciones necesarias para que ésta cumpla sus funciones, caracterizadas en particular desde la función interna. Algunos de estos principios no son más que manifestaciones positivas de la perspectiva interna de la administración de justicia, mientras que otros tienden a hacerla posible o a que no se deforme internamente. En la doctrina procesal tradicional chilena se suele caracterizar a estos presupuestos como "Bases del ejercicio de la jurisdicción”, pero usualmente se incluyen en éstas una gran cantidad de principios que tienen una explicación puramente contingente a una cierta estructuración del poder judicial sin relación explicitada con el cumplimiento de su función. Aquí sólo nos interesa describir brevemente los presupuestos de la administración de justicia que tienen un vínculo directo con la posibilidad de cumplir su función.

a) El principio de sujeción al Derecho, o mandato de sujeción a la ley, es simplemente una manifestación de la función interna del Derecho. La

${ }^{34}$ Aunque no siempre argumentos de este tipo son irrelevantes para los jueces. Es una práctica dada, aunque no usual, el razonamiento en torno a lo que se denomina “policy arguments". Ver por ejemplo: Dworkin, Ronald, Law's Empire (Harvard, Belknap, 1986), pp. 27-29. Pero este tipo de razonamiento suele tener un status complementario a argumentos sobre reglas, o al menos suelen utilizarse sólo cuando no hay reglas previas que determinen con relativa claridad lo que es correcto en un caso determinado. Lo que expresa, por lo tanto, este argumento es la existencia de una regla que diría que en situaciones de indeterminación inmediata de lo correcto, mediatamente se debe considerar correcto lo que acarree menos costos a la sociedad, es decir, lo que estabilice expectativas, conforme a cierta concepción de evaluación de la mejor forma de optimizar la libertad general de acción. Pese a que la existencia de una regla de ese tipo sea conflictiva, no cambia la actitud del juez frente al caso.

${ }^{35}$ Incluso bajo concepciones utilitaristas, la justificación de soluciones dentro de la práctica del Derecho no puede hacerse bajo el principio que justifica a éste, o sería contraproducente a su propia función. Véase: RAwLS, John, cit. (n. 30). 
administración de justicia resuelve sobre conflictos de acción por normas preestablecidas o cuya creación ha sido preestablecida, y cuya forma de preestablecimiento es procedimentalmente representativa. Ese vínculo con normas pre-existentes es la base de su legitimidad. Pero pese a ser una cuestión tan necesaria como evidente en nuestra concepción de la función del Derecho, en su configuración y en su contenido es sin dudas el más complejo de todos los presupuestos de la función judicial. Toda la teoría de la argumentación jurídica no es más que una forma de equilibrar el conflictivo margen de acción que otorga el mandato de sujeción a la ley, de forma de no hacerlo demasiado restrictivo como para sacrificar la posición de los que no pudieron ser considerados explícitamente al legislar, ni demasiado amplio como para diluir la aplicación del derecho en pura argumentación moral.

b) El principio de imparcialidad se deduce ya de la idea misma de jurisdicción, e incluso de la asignación de derechos subjetivos a los individuos. En la concepción general que se tiene de la función judicial y sobre todo en la historia de las instituciones, la imparcialidad del juez es probablemente, antes que la sujeción a la ley, el primer presupuesto que se suele considerar en ésta. La imparcialidad, como presupuesto de la resolución de conflictos por un tercero, no se remonta históricamente sólo al reconocimiento institucional de la función moderna del Derecho, sino que se remonta a concepciones de justicia básica. En ese sentido es manifestación directa del aspecto interno de la función judicial, esto es, de la expresión de una particular pretensión de corrección institucionalizada por un tercero imparcial frente a un conflicto ajeno. Positivamente esto se manifiesta en la regulación de la implicancia y la recusación como formas de inhabilitación de los jueces para conocer $\operatorname{casos}^{36}$, reconocidos de forma genérica en el artículo 196 del Código Orgánico de Tribunales, e indirectamente se manifiesta en casi todos los delitos de jueces contra la administración de justicia.

c) El principio de independencia judicial, que se manifiesta formalmente con una descripción vaga en el artículo 12 del Código Orgánico de Tribunales, y mediante una reserva legal en su manifestación interna descrita en el artículo 8 del mismo Código, no siempre es bien comprendido en su alcance. Entendido de forma simple, este principio supone que si el juez, al conocer de un conflicto, debe solamente dedicarse a resolver el caso conforme a derecho, esto es, debe protegerse el que no se vea influido por presiones externas para fallar de una forma u otra. De una forma más completa, es la manifestación

\footnotetext{
${ }^{36}$ La consideración de la falta de implicancia, y en menor medida de la recusación, como presupuesto del ejercicio de la función judicial es tan fuerte que, en la terminología procesal tradicional chilena, se suele denominar como "incompetencia subjetiva", es decir, ausencia de un presupuesto del ejercicio de la función judicial no en el tribunal sino en la persona del juez.
} 
institucional de la necesidad que el juez pueda y deba ser inmune a toda forma de relación inter-subjetiva externa al proceso en relación con la solución de casos, lo que no se agota en la inmunización frente a presiones externas. El principio de independencia expresa, por lo tanto, varias cosas más. Expresa por cierto una prohibición de recibir cualquier incentivo -negativo o positivo- a la resolución de un caso de una forma u otra. Desde un punto de vista organizacional, expresa la necesidad de proteger al juez de forma tal que ir contra el poder no sea una forma de presión suficiente para hacerlo desviarse de su función. Pero además, desde la organización interna del propio aparato de administración de justicia, expresa la necesidad de la ajenidad de éste, de todo éste, a la resolución de un caso que tenga uno de sus jueces.

Aunque el principio de imparcialidad no tiene un vínculo conceptual de dependencia necesaria de la sujeción al derecho -como se ha dicho, históricamente le antecede-, tanto éste como el principio de independencia no hacen más que proteger al primero. Con la instauración de una administración de justicia legalista, en el sentido de dependiente en la mayor medida deseable del derecho positivado, el principio de sujeción al derecho cobra tal relevancia que pasa a subordinar funcionalmente al resto. Eso lo constituye en la pieza central en la configuración de la administración de justicia.

\section{EL BIEN JURÍDICO DENOMINADO}

Administración de JUSTICIA

La exposición anterior respecto de aspectos específicos de la función judicial y de la administración de justicia en términos no necesariamente ligados a la justificación material de los delitos en análisis, no tiene por objeto sino llevar a cabo la labor de identificación del bien jurídico de forma suficientemente reflexiva y explicativa.

\section{Precisiones metodológicas.}

En la dogmática penal, el principal criterio de sistematización de los tipos de la Parte Especial lo constituye el bien jurídico que éstos protegen, el que sirve además como razón justificativa abstracta de éstos ${ }^{37}$. En el derecho penal nuclear clásico, es decir, aquel que protege principalmente la vida, la integridad física, la libertad y la autonomía sexual como intereses personalísimos; y la propiedad y el patrimonio como intereses individuales instrumentales, la sistematización, sin ser simple, al menos cuenta con criterios básicos para ser llevada a cabo. Pero con la tipificación de distintas conductas con el ob-

${ }^{37} \mathrm{Al}$ respecto, AlcÁcer Guirao, Rafael, Sobre el concepto de delito. ¿Lesión del bien jurídico o lesión de deber? (Buenos Aires, Ad Hoc, 2003), pp. 18 ss. 
jeto de proteger lo que se denomina "bienes jurídicos colectivos", desde ya conflictivos en su posibilidad de congruencia con la idea de bien jurídico ${ }^{38}$, esto se hace mucho más complejo. Y ello en dos períodos. En el derecho penal pretendidamente liberal de las primeras codificaciones, el problema de los bienes jurídicos colectivos ya se conocía precisamente en aquellos tipos que, sin afectar a un solo individuo, eran condiciones de posibilidad del ejercicio del poder estatal. Los delitos contra la administración pública, en general ciertos delitos de funcionarios públicos, y en particular también los delitos contra la Administración de justicia ${ }^{39}$, aunque no constituidos como categoría autónoma, eran manifestaciones de tipos que indudablemente creaban ciertos problemas de explicación y legitimación en una comprensión liberal del bien jurídico ${ }^{40}$, pero que no tuvieron relevancia como para hacer parecer pragmáticamente anómalo este criterio de clasificación. El segundo periodo, en cambio, conocido usualmente como la "expansión del derecho penal", pone en crisis la idea de una concepción en algún sentido operativa del bien jurídico, sea tanto en la posibilidad de excluir ciertos tipos penales, como respecto de la posibilidad de ofrecer criterios claramente delimitables de clasificación ${ }^{41}$.

Pese al carácter conflictivo que ha adquirido el concepto de bien jurídico, desde el punto de vista de la justificación sustantiva y político criminal de la legislación penal, la identificación del bien jurídico protegido en la tipificación es esencial por dos razones. En primer lugar porque, desde el punto de la

${ }^{38}$ Para una aproximación al desarrollo de la teoría del bien jurídico: Roxin, Claus, Derecho penal Parte general, I: Fundamentos y estructura de la teoría del delito (Madrid, Civitas, 1997), pp. 51 ss.; AlCÁCER GUIRAO, cit. (n. 37), pp. 119 ss.

${ }^{39}$ Respecto de lo anterior, véase: por ejemplo Roxin, cit. 8n. 38), p. 54; HASSEMER, Winfried, Derecho penal y Filosofía del Derecho en la República Federal de Alemania, en El mismo, Persona, mundo y responsabilidad: bases para una teoria de la imputación en el Derecho penal (Santa Fe de Bogotá, Temis, 1999), p. 7.

${ }^{40} \mathrm{La}$ explicación decimonónica de la existencia de (lo que hoy se consideran) delitos contra la administración de justicia no era a-problemática. En la concepción binaria de la justificación material del derecho penal de Feuerbach, sólo serían legitimables tipos establecidos para la protección de un derecho subjetivo o de la existencia del Estado. Como en el caso de delitos de particulares en el proceso no parece darse ninguna de las dos cosas, Feuerbach sostuvo la tesis que en realidad afectan derechos subjetivos de la persona en contra de la cual se declara. Esta reconstrucción, como sostiene Kindhäuser, es implausible: no puede sostenerse ello cuando se declara falsamente contra un acusado. Al respecto, KINDHÄUSER, Urs, Estructura y legitimación de los delitos de peligro, en InDret 1 (2009) [www.indret.com].

${ }^{41} \mathrm{Al}$ respecto, véase: Silva SÁnchez, Jesús María, La expansión del Derecho penal: aspectos de la politica criminal en las sociedades postindustriales (Madrid, Civitas, 2001); Silva SÁnchez, Jesús María, Aproximación al Derecho penal contemporáneo (Barcelona, Bosch, 1992), pp. 15-17. 
aplicación de la normativa que se construye, una sistematización teleológica a la luz del objeto de protección permite alcanzar grados de reflexividad dogmática muy superiores a los que alcanza una regulación ciegamente agrupada: ella le otorga apertura a la argumentación interpretativa teleológica. En el desarrollo de la dogmática de las condiciones generales de la punibilidad de tipos especiales, la identificación clara de un bien jurídico protegido en los tipos de la Parte Especial es un paso esencial ${ }^{42}$. Pero además de esta función adscriptiva y argumentativa auxiliar, la identificación del bien jurídico es importante en tanto permite una justificación suficiente de la tipificación penal general, esto es, no sólo de los criterios de punibilidad sino ya de la restricción de la libertad que se constituye mediante la norma de comportamiento que subyace a las disposiciones penales de la Parte Especial ${ }^{43}$.

El juego de estos dos factores de relevancia del bien jurídico, a saber poder heurístico y potencial justificador y limitador, es lo que hace que la identificación del bien jurídico protegido no sólo sea esencial como tarea legislativa de justificación, sino que además explique el que se trate del criterio más sensato y más productivo para clasificar los tipos de la Parte Especial.

En lo que sigue se llevará a cabo derechamente una reconstrucción del bien jurídico Administración de justicia a partir de los presupuestos metodológicos definidos. Para ello, se mostrarán ciertos problemas generales que sufren las reconstrucciones dogmáticas tradicionales, se describirán algunas de las teorías que se han construido al respecto, criticándolas, y se desarrollará finalmente una reconstrucción que no sufra de esas críticas y que pueda hacer frente a los problemas que afectan a la categoría.

\section{Problemas propios de la categoría en la identificación del bien jurídico.}

La identificación de un objeto de protección Administración de justicia se encuentra sujeta a una serie de problemas relevantes. Como bien jurídico supra-individual, desde un principio es probable caer en la construcción semántica de abstracciones sin contenido específico para justificar el reforzamiento penal de determinadas normas de comportamiento. Pero además,

${ }^{42}$ Cfr. Alcacer Guirao, Rafael, cit. (n. 37), pp. 18 a 20 y 137 ss. . Respecto de su función en la interpretación, SchÜNEMANN, Bernd, El principio de protección de bienes jurídicos como punto de fuga de los limites constitucionales de los tipos penales y de su interpretación, en HeFENDEHL y otros, La teoría del bien jurídico. ¿Fundamento de legitimación del derecho penal o juego de abalorios dogmático? (Madrid, Marcial Pons, 2007).

${ }^{43}$ Sobre las razones que explican la particular necesidad de justificación sustantiva del establecimiento de una ley penal, véase: BAscuñán Rodríguez, Antonio, Comentario crítico a la regulación de los delitos contra el medio ambiente en el Anteproyecto de Código Penal de 2005, en Estudios Públicos. Revista de Humanidades y Ciencias Sociales, 110 (Santiago, 2008), p. 251. 
uno de los problemas más serios que debe enfrentar la construcción de una categoría de esta clase es que comprende tanto delitos típicamente funcionarios como delitos cometidos por particulares. Parte importante de la dogmática comparada, precisamente en atención a este problema y también para centrarse en el tema mucho más relevante desde un punto de vista político criminal de la corrupción, deja de lado las consideraciones sobre los delitos cometidos por particulares al intentar construir un concepto de bien jurídico "Administración de justicia". Si bien el fenómeno no es exclusivo a los delitos contra la administración de justicia, ya que en las otras áreas de delitos funcionarios también existen delitos que no son especiales propios, la diferencia entre los delitos típicamente reducidos a autoría de funcionarios, como la prevaricación de los jueces, y los delitos típicamente particulares, como la obstrucción a la justicia o el encubrimiento, es particularmente fuerte, y además no existe una preponderancia cuantitativa de los delitos funcionarios. En esto la categoría de la Administración de justicia es especialmente conflictiva.

También es importante tener en cuenta que tanto en la doctrina nacional como en el derecho comparado, no siempre se distingue entre las categorías "delitos contra la Administración de justicia" y la categoría "delitos contra la administración pública”. Usualmente no se practica esa distinción en contextos en que el derecho vigente no efectúa la distinción, cómo por ejemplo en Alemania, o en Colombia. Pero esa decisión de tratamiento conjunto también se toma, a veces, en contextos en que sí existe la distinción, cómo en España, o suele hacerse la distinción en contextos en que no existe positivamente ésta, como en Chile. Ello hace que no todas las construcciones sean directamente comparables entre sí.

\section{Reconstrucciones del bien jurídico de la Administración de justicia.}

Sin tomar en consideración si se realiza la distinción entre administración de justicia y administración pública, a continuación se expondrán a rasgos generales las principales reconstrucciones de la Administración de justicia como bien jurídico, agrupadas por su grado de similitud pero exponiendo las particularidades de cada una y, en lo posible, sus ventajas y debilidades. Posteriormente se defenderá cuál es la teoría correcta y se mostrarán las consecuencias que pueden sacarse de ésta.

a) Determinación por criterios institucionales. Una forma posible, aunque errada, de construir un bien jurídico colectivo es considerar su identificación simplemente como un ejercicio de aglutinamiento conceptual. En general, estos intentos se plantean de forma tan amplia que no tienen problemas de inclusión de todos los tipos de la categoría que corresponda, y desde ese punto de vista no pueden ser criticados. Pero su potencial explicativo de 
la legitimidad de la persecución penal en este ámbito, y sus consecuencias heurísticas, son débiles al punto de ser casi inexistentes. Es por ello que se trata de la forma más débil de llevar a cabo la labor en cuestión.

En materia de delitos contra la Administración de justicia, en esta línea en España, por ejemplo, se encuentra Muñoz Conde. En su manual de Parte Especial, éste reconduce el bien jurídico Administración de justicia a un criterio institucional impreciso. Serían delitos contra la Administración de justicia los que tengan "relación con el Poder Judicial" ${ }^{4}$. El criterio no sólo no entrega argumentos que permitan reconocer la razón de la importancia del objeto de protección, de forma de explicar la tipificación, pero además el criterio no puede jugar ningún papel decisivo en la interpretación y reconstrucción racional de la categoría, y ni siquiera, pese su generalidad, permite comprender verosímilmente los tipos que se enmarcan en el Código Penal español. Esto porque de lo que se trata es precisamente de precisar qué es esta "relación" con el Poder Judicial. Naturalmente, todo tipo penal tiene alguna relación con el Poder Judicial, ya que éste es el encargado de su aplicación. Pero en el caso de los delitos contra la Administración de justicia, se trata evidentemente de una relación más fuerte que ésta. Y ésta tampoco puede ser suficientemente restrictiva como para exigir ser efectuada por el Poder Judicial, ya que no sólo hay delitos especiales propios, y ni siquiera en el Poder Judicial, ya que otros tantos, como el encubrimiento, pueden no ser realizados en el contexto especial del proceso. Por ello, el criterio no es satisfactorio ni aún en su pretensión de poder abarcar todos sus tipos al formularse de forma general ${ }^{45}$.

En un estudio más minucioso sobre el tema, pero con las mismas pretensiones erradas, Donna pretende reconducir a los Delitos contra la administración pública a un bien jurídico determinable por criterios institucionales más flexibles. No se trataría sólo de la conjunción del Poder Judicial y del resto de la administración pública, lo que correspondería a un concepto propio del Derecho administrativo, sino que en materia penal sería necesario hacerlo más extensivo ${ }^{46}$. Para ello, construye un concepto que tenga una amplitud mucho mayor, y que lo caracteriza cómo "el gobierno del Estado totalmente integrado con los poderes que lo componen y con los servicios

${ }^{44}$ Muñoz Conde, Francisco, Derecho penal. Parte especial (Valencia, Tirant Lo Blanch, 2004), pp. 918-919.

${ }^{45}$ En la misma línea se encuentra una parte importante de la doctrina penal en lengua española. Con mayor detalle en Rodríguez Collao, Luis - OsSANdón WIDow, María Magdalena, Los Delitos contra la función pública (Santiago, Editorial Jurídica de Chile, 2005), p. 161.

${ }^{46}$ Donna, Edgardo Alberto, Derecho penal. Parte especial (Buenos Aires, RubinzalCulzoni Editores, 1999), pp. 11-12. 
que son inherentes a la naturaleza de esos poderes o que el Estado atrajo a su esfera por razones práctica y en orden a finalidades pública, sea que las realice con organismos específicamente administrativos o por medio de organismos autárquicos, aun cuando éstos constituyan entidades jurídicas y en ellos intervengan particulares con sus aportes" ${ }^{37}$. El bien jurídico lo construye, por lo tanto, sumando cuestiones accesorias al núcleo de lo que constituiría a la administración pública. Con ello, todos los tipos en cuestión podrían ser reconducidos a este objeto protegido. Pero es evidente que el concepto que construye sufre de una serie de problemas importantes. En primer lugar, porque no explica la razón de la protección penal. El concepto tiene una pretensión exclusivamente clasificadora y agrupadora, y no permite reconducir la protección del objeto colectivo que pretende identificar al interés de todos. Pero además el concepto que entrega para identificar el bien no parece ser más que una suma de cuestiones diversas cuya unidad la constituye exclusivamente la tipificación contingente. Y eso no es el objeto de la construcción de un bien jurídico. Este es precisamente el gran problema que sufren todas las construcciones enmarcadas en esta categoría ${ }^{48}$.

b) Verdad y fe pública. Parte de la doctrina nacional y comparada ${ }^{49}$, respecto de algunos delitos que se suelen identificar como atentados cometidos por particulares contra la Administración de justicia, lo agrupan bajo consideraciones que se acercan a la idea de verdad en contextos institucionales. Lo que se protegería no sería una institución, como en las teorías anteriores, sino que se reforzaría la confianza en la fiabilidad de la institución. Es decir, se intentaría reforzar algunos presupuestos necesarios para el cumplimiento de la función de la Administración de justicia, tanto desde la perspectiva de la veracidad de los hechos que en ella se invocan, como desde de la perspectiva de su imparcialidad.

En la doctrina chilena la posición de Garrido Montt es ilustradora al respecto. Pese a que éste reconoce que hay tres objetos distintos que podrían considerarse lesionables en el título $4^{\circ}$ del libro II del Código Penal, y que entre ellos los tipos del párrafo 7 podrían ser considerados delitos contra la Administración de justicia ${ }^{50}$, al referirse en particular a este párrafo descarta esta posibilidad en nuestra codificación porque pese a que exista una lesión "mediata * ( al poder que tiene el Estado como titular de la facultad

${ }^{47}$ Ibíd., p. 12.

${ }^{48}$ Para otras críticas, véase: Rodríguez Collao - Ossandón Widow, cit. (n. 45), p. 156.

${ }^{49}$ Ibíd., p. 97, con mucha precisión.

${ }^{50}$ Garrido Montt, Mario, Derecho penal. Parte especial (Santiago, Editorial Jurídica de Chile, 2000), IV, pp. 10 y 11. 
jurisdiccional"s1, "en el hecho lo prohibido es faltar a la verdad objetiva" 2 . Otra de las razones que reconoce Garrido Montt para inclinarse por quienes agrupan el bien jurídico en relación con la verdad, en el gran objeto de protección "fe pública", es que puede explicar de mejor forma la sistematización del Código Penal. Lo último es, en una reconstrucción de orígenes, parcialmente cierto. Tal como lo señala Garrido Montt, en la codificación de esta clase de delitos se tuvo como modelo el Código Penal español de 1848 y el Código Penal belga. El primero, agrupaba esta clase de delitos bajo "las falsedades". El Código Penal belga de 1867, por su parte, derechamente clasificaba en relación con la fe pública ${ }^{53}$. Lo que se hizo en el Código Penal, fue fusionar ambas consideraciones -y agregar a continuación "el falso testimonio", ya que todas tendrían cercanía conceptual imprecisa con la protección de la "verdad".

Sin embargo, pese a que el criterio que haya utilizado en su momento el legislador haya dicho relación con el rechazo a la falsedad, y por lo mismo el objeto de protección tenido en mente haya sido la verdad o la confianza, existen una serie de inconvenientes imposibles de superar en la reconstrucción racional de un objeto de este tipo. El primero es que tratándose de delitos de falso testimonio, el núcleo de la clase que Garrido Montt trata de explicar, la referencia a la verdad confunde la norma de comportamiento con el objeto de protección. Una cosa es la obligación del testigo de comportarse de determinada forma, de decir lo que él cree es toda la verdad, y otra cosa es la razón que se encuentra tras esa obligación, y tras el refuerzo penal parcial a esa obligación, y el objeto que se afecta mediante la falsedad. Sin su grado de sofisticación, esta teoría precisamente se rehúsa a hacer lo que Jakobs se rehúsa a hacer de forma general: hacer algo más que explicitar los deberes configurados por normas jurídicas como objeto de protección penal. Esto es, Garrido Montt simplemente repite la idea de que lo que se protege es una obligación jurídica, un deber. Garrido Montt de hecho hace explícita la idea, al citar a Etcheverry quien sostiene que lo que se encuentra detrás del falso testimonio es "la infracción del deber que la ley impone de decir la verdad cuando se declara en calidad de testigo en proceso seguido ante la autoridad judicial" 54 . Esto es, de forma sorpresiva, exactamente la tesis de legitimación sustantiva de Jakobs: lo que protege la pena es el deber configurado por la norma de comportamiento en cuestión, pero no hay un bien abstracto específico superior a ese deber que sea posible identificar.

Por cierto, la existencia de deberes especiales del testigo es evidente, pero

\footnotetext{
${ }^{51}$ Ibíd., p. 107.

${ }^{52}$ Ibíd.

${ }^{53}$ Ibíd., p. 105.

${ }^{54}$ Ibíd. p. 108.
} 
no es suficiente para fundamentar su castigo penal por la infracción de esa obligación. De lo que se trata es precisamente de clarificar qué es lo que se protege cuando sólo en ese contexto existe un refuerzo penal de la sinceridad del comunicante a través de un reforzamiento de su obligación de sinceridad, y porqué ello es justificable. Y, en segundo lugar, es evidente que su formulación no alcanza agrupar otros delitos de la categoría.

Con ello, la única forma posible de formular un bien jurídico cercano a la verdad sería de forma indirecta, en relación con la confiabilidad del sistema en poder producirla. En Chile, parte de la doctrina procede de este modo. Matus, Politoff y Ramírez, por ejemplo, explican la idea que la Administración de justicia sea un bien jurídico, expresándolo en términos de intereses públicos. Existiría un interés público en "la fiabilidad del establecimiento de los hechos en los procesos judiciales y en ciertas otras actuaciones judiciales" 55 . El criterio pretende poner énfasis en la relación de dos aspectos centrales que recorren a algunos de los tipos de la categoría: el proceso y la prueba, dejando un criterio residual para lo que no pueda ser comprendido en ambos conceptos anteriores.

Pese a que el criterio, no exento de imprecisiones, es relevante en los delitos que se producen en el proceso y que afectan la fragilidad epistémica de la prueba, como paradigmáticamente sucede con el falso testimonio, éste no es del todo preciso, ya que varios de los delitos centrales de la categoría no tienen relación con una afectación de la justificación externa de premisas fácticas, lo que no sucede incluso en el caso del delito paradigmático contra la Administración de justicia, como es la prevaricación judicial. Es decir, esta concepción no permite incluir como delito contra la Administración de justicia al delito central de la categoría: la prevaricación judicial. Por ello, debe ser descartada como criterio general. Asimismo, esta concepción no ofrece ningún criterio de justificación del objeto de protección -sólo responde a la pregunta por el objeto, no por el fundamento de protección-, en condiciones que si se determina que ese es el interés que debe ser protegido, ello afectaría fuertemente la interpretación de la categoría.

Pese a que sean demasiado estrechas e imprecisas para poder permitir construir un concepto de bien jurídico Administración de justicia, estas teorías tienen un mérito importante en la explicación de una parte de los delitos contra la Administración de justicia. Como se explicará más adelante, el contexto específico del proceso, que no es más que un contexto construido para ser confiable en condiciones de particular fragilidad epistémica, es par-

${ }^{55}$ Matus, Jean Pierre - Politoff, Sergio - Ramírez, María Cecilia, Lecciones de Derecho penal chileno (Santiago, Editorial Jurídica de Chile, 2003), p. 213. 
ticularmente importante en la justificación y explicación de algunos tipos de la categoría y que se relacionan efectivamente con la idea de fiabilidad.

c) Otras reconstrucciones. Como cualquier bien jurídico colectivo, y pese a su aceptación histórica, existen numerosas formas de reconstruir el bien jurídico Administración de justicia, las que se hacen sobre todo a partir de la utilización de otros términos semánticamente imprecisos, sólo a veces precisados por quien los propone. Así, por ejemplo, sucede con la idea que se protege "la justicia" ${ }^{56}$. Cuando se mantienen este tipo de conceptos como meras manifestaciones semánticas, son evidentemente inútiles. Cuando se las trata de precisar, en cambio, en general reconducen a ideas que no son inmediatamente asimilables al concepto semántico que se propone, y se acercan a algunas de las ideas tradicionales ya descritas, o a la que se desarrolla más adelante. Por ello, no vale la pena tratarlas aquí.

\section{La Administración de justicia como presupuesto especifico de la libertad} general de acción en una sociedad compleja.

a) El fundamento de protección del bien jurídico Administración de justicia. Conforme a lo que ya se expuso en la primera parte, puede verse con claridad como, en primer lugar, en la estructuración de las sociedades modernas, la institucionalización del Derecho es esencial para la coordinación de la acción. La Administración de justicia, en ese esquema, cumple la función específica de estabilizar expectativas normativas, y por lo mismo es un presupuesto específico de la libertad general de acción. Para ello, la Administración de justicia se constituye en torno a ciertos presupuestos necesarios para poder lograr ese cometido en una sociedad compleja y democrática.

Los ataques contra la administración de justicia, las acciones lesivas que afectan a los presupuestos de la Administración de justicia de una forma particularmente intensa, son, en un sentido muy específico, afectaciones a la posibilidad de la libertad en una sociedad moderna. No se trata de afectaciones a una libertad de acción concreta e individual, pese a que puedan producirse afectaciones a libertades individuales en delitos contra la Administración de justicia, las que, sin embargo, no tendrían relevancia específica salvo en cuestiones concursales o, eventualmente, en la determinación de la penalidad ${ }^{57}$. Precisamente por esta falta de vínculo intrínseco con libertades individuales, los delitos contra la Administración de justicia no constituyen delitos contra intereses individuales.

\footnotetext{
${ }^{56}$ Sobre el particular y sus críticas, véase: RodRíguez COLLAO - OsSANDÓN WIDow, cit. (n. 45), p. 159 a 162.

${ }^{57}$ Como se verá más adelante, esta es la situación de varias codificaciones moderna y, en algún sentido, incluso del Código Penal chileno.
} 
Por cierto, exigir un resultado de lesión de libertad individual específica, cómo manifestación de coacción ilegitima por no estar revestida de formas jurídicas, sería una forma posible de configurar a estos delitos. De hecho, varios delitos que algunos autores suelen agrupar como ataques parciales a la Administración de justicia, constituyen delitos contra la libertad, y así lo reconocen éstos ${ }^{58}$. Es perfectamente pensable un sistema que, para prescindir en el Derecho penal de bienes jurídicos colectivos, organice como delitos contra la libertad, o contra otros bienes jurídicos individuales, a ciertos delitos que se suelen agrupar como delitos contra la administración pública o contra la Administración de justicia. Ese sistema, para evitar lo que consideraría un procedimiento de auto-degradación, dejaría las áreas no lesivas de derechos individuales en manos de sanciones administrativas, y exigiría un resultado lesivo reconducible a intereses personales en los delitos en cuestión. Así por ejemplo la prevaricación, delito que en principio, en el nivel de la punibilidad $^{59}$, no requiere necesariamente de un resultado lesivo a un particular, se configuraría de forma tal que exigiera un afectado particular, y que esa afectación a esa persona se tradujera en lesión de la libertad (por ejemplo, privación de libertad definitiva o cautelar). Pero pese a que ese sistema sea posible, algunos dirían incluso sensato, es absolutamente inverosímil frente a la legislación vigente. Como ya se dijo, en nuestra tradición, los delitos contra la Administración de justicia no son una clase de delitos contra la libertad.

De lo que se trata es de la afectación de una condición de posibilidad específica de la libertad general de acción: la Administración de justicia como estabilizador del contexto social que permite la libertad general de acción. Los delitos contra la Administración de justicia tienen como objeto de protección exclusivamente esa condición de posibilidad. Son tipos que se agrupan entre sí, y que justifican prima facie su punibilidad, en el hecho que protegen una condición esencial para la posibilidad de la libertad general de acción en una sociedad moderna, esto es: que la Administración de justicia pueda estabilizar expectativas normativas. Los delitos contra la Administración de justicia tienden a impedir la posibilidad de estabilizar expectativas normativas, ya sea afectando directamente la intangibilidad de sus presupuestos teóricos -reseñados como principios-, ya sea atacando otros presupuestos ligados de forma contingente pero esencial al correcto cumplimiento de su función, en particular el proceso y la investigación penal.

Por cierto, del hecho que proteger esa condición de posibilidad de la libertad sea necesario no quiere decir directamente que ese criterio pueda

${ }^{58}$ Por ejemplo MuÑoz Conde, cit. (n.. 44), p. 920, califica a las detenciones ilegales cómo delitos que afectan en su "aspecto ideológico" a la administración de justicia.

${ }^{59} \mathrm{No}$ así en el nivel de la penalidad. Ver Infra. pp. 179 ss. 
explicar todos los tipos que se agrupan en la categoría. La forma que asume el ataque en cada sub-categoría de tipos y las razones por las que produce una lesión de bien jurídico es una cuestión que debe ser estudiada en cada una de estas sub-categorías. Pero el criterio en cuestión sí permite llevar a cabo la primera labor de la construcción de un concepto de bien jurídico, a saber entregar una justificación sustantiva prima facie de la categoría.

La construcción de un bien jurídico de estas características resulta ciertamente muy distinta a aquella de los bienes jurídicos individuales tradicionales. Dos son las características que lo diferencian más claramente de éstos. En primer lugar, su carácter supra-individual. La justificación de la punición no se refiere la afectación de los derechos o de los bienes de un otro específico. Sólo cuando el bien jurídico en cuestión es afectado de forma masiva, se ven afectados derechos o bienes de otros por la pérdida de vigencia de ese bien. Pero eso no lo realiza ninguna acción particular. Se trata en cambio de la protección de condiciones de posibilidad de esos derechos del grupo, de la protección de la configuración de toda la comunidad ${ }^{60}$. Precisamente ese es el segundo carácter distintivo de esta clase de bienes jurídicos colectivos. Son bienes secundarios, bienes que se remiten a los bienes jurídicos primarios, que sólo se justifican en relación con éstos. La existencia de la Administración de justicia, y su correcto funcionamiento, es un presupuesto del ejercicio de la libertad general de acción conforme a una ley general. Pero además es un presupuesto evidente para la existencia de la propiedad y del patrimonio ${ }^{61}$, y para la configuración normativa de la vida, la libertad sexual, y en general de todos los bienes jurídicos individuales. Es esa condición de posibilidad, contingente y configurada de modo contingente, la que se protege.

${ }^{60}$ Ello puede verse con claridad tanto conforme con los criterios que entrega $\mathrm{He}-$ fendehl, cuanto se acuerdo con la teoría de Müssig, se trata de bienes jurídicos colectivos. Respecto del vínculo entre posibilitación de la libertad general de acción y bienes jurídicos colectivos, véase: KaHLO, Michael, Sobre la relación entre el concepto de bien jurídico y la imputación objetiva en el derecho penal, en HEFENDEHL y otros, La teoría del bien jurídico. ¿Fundamento de legitimación del derecho penal o juego de abalorios dogmático? (Madrid, Marcial Pons, 2007), pp. 56 ss. .

${ }^{61}$ En el mismo sentido: JаковS, Günther, ¿Qué protege el Derecho penal, bienes jurídicos o la vigencia de la norma? (Mendoza, Ediciones Jurídicas Cuyo, 2001), p. 19. En la filosofía moderna, en particular en la tradición liberal británica y en Kant, es usual considerar a la instauración del derecho como condición de posibilidad, sobre todo, de la propiedad como manifestación de lo que pertenece al hombre (cuerpo, libertad y bienes). Hegel, por su parte, considera que el derecho constituye a la personalidad, fundamento de todo el derecho abstracto, la propiedad, existencia inmediata de la libertad en relación consigo misma, y del contrato, relación diferenciada de una persona con otra en calidad de propietario, y por lo tanto es condición de los tres. Véase: Hegel, G.W.F., cit. (n. 33), pp. 59 ss., 96 ss. y 206 ss. 
Los delitos contra la Administración de justicia funcionan así en un plano curioso. Todo el Derecho penal se constituye en relación con la protección de otros bienes, distinguibles en algún sentido de sí mismo. Incluso si se sostiene una teoría normativista, o una justificación de la pena puramente retributiva, el vínculo con la posibilitación de la propiedad y, en un sentido general, de la personalidad, es indesmentible. Aquí simplemente se sustituiría el carácter preventivo de la pena a un carácter únicamente expresivo de la corrección, o de la existencia, de éstos ${ }^{62}$. Así la Administración de justicia sería exclusivamente un objeto constituido como objeto protector. Lo anómalo en los delitos contra la Administración de justicia es que ésta se constituye en un objeto protegido por sí mismo. Aquí se superpone el carácter protector de la Administración de justicia, con un carácter único, al menos penalmente, de objeto protegido. Con ello no sólo se trata de delitos anómalos porque lo que se protege es la falta de producción de un bien jurídico, como se suele afirmar respecto de bienes institucionales, sino que su principal anomalía radica en este desdoblamiento del bien protector en bien protector y bien protegido por sí mismo. Ello no es extensible a ningún otro bien jurídico colectivo $^{63}$, ni puede ser tampoco completamente explicado por la reducción del delito a infracción de deber.

b) Construcciones similares de la Administración de justicia y críticas. Esta construcción del bien jurídico, en términos generales, no pretende ser completamente novedosa. Parte importante de la doctrina tanto en Alemania, como en España e incluso en Chile ${ }^{64}$, llega a conclusiones similares, aunque con formulaciones y presupuestos distintos.

Así, de forma también parecida, aunque con diferencias metodológicas

${ }^{62}$ Sobre el alcance del carácter expresivo de la pena en una justificación retributiva de ésta, véase: Mañalich, Juan Pablo, La pena como retribución, en Estudios Públicos, 108 (Santiago, primavera de 2007), pp. 29 ss.

${ }^{63} \mathrm{Ni}$ siquiera completamente en los delitos contra la Administración Pública. El papel expresivo de reproche, y de corrección del comportamiento correcto de la Administración, radicaría igualmente en la administración de justicia. Incluso si existiera algo así como delitos contra la legislación, que en principio dependieran de los deberes de los legisladores, el objeto protector sería distintos del objeto protegido. Porque pese a que quienes constituirían o reforzarían el deber de comportamiento serían quienes "producen" derecho, su protección quedaría radicada en la administración de justicia.

${ }^{64}$ Pueden encontrarse comprensiones similares derechamente en la conceptualización general del bien jurídico que realizan algunos autores. Roxin, de hecho, en su conceptualización del Bien Jurídico introduce como parte del concepto a las "circunstancias dadas [...] que son útiles [...] para el propio sistema”, en Roxin, Claus, cit. (n. 38), p. 56. Rudolphi hace lo propio en su concepto, citado por HefendeHL, Roland, ¿Debe ocuparse el Derecho penal de riesgos futuros? en Revista Electrónica de Ciencia Penal y Criminología, 04-14 (2002) [http://criminet.ugr.es/recpc], p. 3. 
importantes, se refiere Jakobs a los delitos contra la Administración de justicia al presentarlos como un ejemplo de una categoría que la teoría del bien jurídico no puede alcanzar a explicar. Jakobs, al intentar reconstruir de la forma más verosímil posible al bien jurídico Administración de justicia para luego refutar por inútil e implausible una construcción tal, como test de verosimilitud de la teoría del bien jurídico, demuestra que se trata de una condición de posibilidad de las formas de convivencia que se reconocen en sociedad $^{65}$, es decir, entrega un concepto sumamente similar al aquí defendido. Pero, según Jakobs, del hecho que la Administración de justicia posibilite bienes, no se deduciría que ella misma sea un bien ${ }^{66}$, ya que lógicamente en los delitos contra intereses individuales puede distinguirse entre la acción lesiva y el bien que se lesiona. Sólo de ser al menos posible hacer esa diferenciación, tendría sentido construir un concepto trascendente de bien jurídico. En cambio, tratándose de los delitos contra la Administración de justicia, sucedería exactamente lo contrario. La lesión no se produciría en algo que sea posible distinguir de la acción, sino que el incumplimiento del deber del juez implicaría la no producción del bien ${ }^{67}$. Jakobs no quiere decir, sin embargo, que no sea posible re-configurarlo de forma más convincente como bien, ahora dependiente de normas, pero sí que configurarlo derechamente como infracción de deber sería, por lo mismo, más adecuado y más simple ${ }^{68}$.

Con ello, la crítica central de Jakobs se refiere a la falta de verosimilitud de la reconstrucción de deberes en bienes. Esto, sin embargo, sucede sólo si se entiende la idea de bien jurídico en términos excesivamente naturalistas y ligados a teorías fuertemente preventivas de la pena. Nada de eso se pretende hacer aquí. Como ya se ha expuesto, el bien jurídico no constituye más que el objeto protegido en un alto grado de abstracción de varios tipos, y la justificación sustantiva discursiva común que comparten esos tipos. Sólo

${ }^{65}$ Sobre todo de la propiedad, en lo que sigue la tradición de la filosofía moderna. Esto es un tema central en la dogmática de Jakobs, tomado de los Principios de la Filosofía del Derecho de Hegel. La propiedad, en sentido amplio, representa el ámbito central de la capacidad de organización que el Derecho le otorga a la persona. Sobre ello, véase: JаковS, Günther, Consumación material en los delitos de lesión contra la persona, en Revista Electrónica de Ciencia Penal y Criminología, 04-13 (2002) [http:// www.criminet.ugr.es/recpc].

${ }^{66}$ Ello reproduce en forma imprecisa lo que ya se dijo del desdoblamiento de la administración de justicia en esta categoría.

${ }^{67}$ Es sumamente importante mostrar la contradicción que esto tiene con la idea del derecho penal liberal clásico que las obligaciones de las que se derivan sanciones penales alcanzan sólo a omisiones. Véase: GÜNTHER, Klaus, De la vulneración de un derecho a la infracción de un deber. ¿Un cambio de paradigma en el derecho penal? en La insostenible situación del derecho penal (Editorial Comares, Granada, 2000), p. 491.

${ }^{68}$ En todo, JаковS, Günther, cit. (n. 61), pp. 19 ss. . 
si se comparten las premisas preventivas de la concepción mayoritaria del bien jurídico, en la que lo que siempre hace el Derecho penal es tender a prevenir el daño futuro a bienes, no resulta posible explicar en términos de bien jurídico los llamados delitos de infracción de deberes especiales ${ }^{69}$. Pero las pretensiones de la introducción del concepto de bien jurídico aquí son mucho más humildes. La idea central que hace que la crítica de Jakobs no sea aplicable a la concepción aquí defendida, es que el bien que se protege en nuestra concepción es una conjunción de normas, las normas de comportamiento que constituyen a la función judicial y a formas de solidaridad con ésta. Ellas, por cierto, son constitutivas de un deber, pero su valor no se deduce del carácter de deber que tienen. Ese valor que justifica la instauración y el reforzamiento de esas normas, es el bien jurídico.

También apunta parcialmente a lo mismo la parte de la dogmática alemana que sostiene que el objeto de protección se encuentra constituido por la protección de la confianza. Así, se sostiene usualmente que el adecuado cumplimiento de la función sólo puede hacerse en condiciones de confiabilidad de las decisiones de los tribunales. Este criterio tiene relevancia argumentativa, si se considera que la prestación que entrega la Administración de justicia es dependiente de la capacidad de interacción comunicativa con los miembros de la sociedad. Ello aclara la relevancia de la confianza: es ésta la que permite el desempeño comunicativo del subsistema judicial y, dentro de éste, incluso su funcionamiento. Pero pese a que en ciertos delitos contra la Administración de justicia, típicamente en delitos de falsedad, existan aspectos de confianza directamente comprometidos como condiciones de funcionamiento de la Administración de justicia, ello no es así en todos los tipos que agrupa la categoría. No es así claramente en el delito de prevaricación -nuclear en la categoría-, ni lo es en todas las hipótesis de obstrucción a la justicia. En ese sentido, la teoría de la confianza se limita a sí misma innecesariamente cuando se detiene en un criterio reconducible directamente sólo a una sub-categoría.

Mayor acierto tiene la teoría del correcto funcionamiento de la Admi-

${ }^{69} \mathrm{Y}$ así se explica la llamada "barrera definicional" que le atribuyen algunos autores a Jakobs, con la que no permitiría reformular de forma convincente el bien jurídico en los delitos de infracción de deber especial. No es que se trate de un problema semántico que lleva a una formulación estática, y no dinámica, del bien jurídico. Pero si se pretende explicar el derecho penal relacionándolo exclusivamente con la protección futura de bienes determinados, ello necesariamente depende de que los bienes en cuestión sean respetados mediante abstención. Respecto de la crítica, Cfr. AlCÁCer Guirao, Rafael, cit. (n. 37), p. 134; y Peñaranda Ramos, Enrique - Suárez González, Carlos - Cancio Meliá, Manuel, "Prólogo" a Estudios de Derecho penal (Madrid, Editorial Civitas, 1997), p. 35. 
nistración de justicia y sus derivados. Una versión de esta teoría ha sido defendida en Alemania, por ejemplo, por Kindhäuser.

En al menos dos contextos distintos, Kindhäuser ha propuesto justificaciones para una teorìa de este tipo. En el primer caso, la defensa de la tesis tiene lugar en el contexto del análisis general de los delitos vinculados a la corrupción. Tratándose de la corrupción en el Estado, Kindhäuser considera que los distintos tipos involucrados en la cuestión en Alemania no pueden reconducirse ni a protección de la voluntad del Estado frente a falsedades, por inverosímil y difícilmente justificable ${ }^{70}$, ni a la protección de la confianza en la administración, ya que si fuera la confianza lo que se protege, a menor confiabilidad del objeto de protección, menos digno de protección sería el objeto. Y eso sería contrario a la función del Derecho penal ${ }^{71}$. La única respuesta satisfactoria que Kindhäuser encuentra en relación con el objeto de protección en los tipos relacionados con la corrupción, es que se trata de proteger el poder de decisión frente a intereses particulares. Básicamente se cautela porque el poder de decisión cumpla con independencia e imparcialidad, y eso sería extensible a la Administración de justicia ${ }^{72}$.

En el segundo caso, en cambio, en un artículo referido a la legitimación de los delitos de peligro ${ }^{73}$, Kindhäuser intenta mostrar como en los delitos de peligro, incluidos los delitos de peligro abstracto, son particularmente idóneos para proteger ciertos bienes jurídicos. Su ejemplo central al respecto es la administración de justicia. Siguiendo la concepción de Jakobs, Kindhäuser vincula la protección de la administración de justicia no sólo a su no lesión en sentido puramente negativo, sino a la afectación de la posibilidad de producción de un bien relevante. Con esto, ello empalma con la postura defendida respecto de la corrupción: en todos los casos, se trata de la protección de condiciones de producción de un bien relevante. Esto es, la administración de justicia se vería lesionada cuando no puede producirse, es decir, cuando el derecho no puede aplicarse (o ve afectada su capacidad de producción) en las condiciones en que debe hacerse.

Ambas conclusiones tienen que considerarse correctas. Como ya se vio, en un objeto configurado institucionalmente en condiciones contingentes que permite que éste cumpla una función normativa, ciertos presupuestos designables en abstracto como principios (por ejemplo: sujeción al derecho, imparcialidad) requieren ser protegidos. Los delitos contra la administra-

\footnotetext{
${ }^{70}$ Kindhäuser, Urs, Presupuestos de la corrupción punible en el Estado, la Economía y la Sociedad. Los delitos de corrupción en el Código Penal alemán, en Política Criminal, 3 (2007) [A1, [http://www.politicacriminal.cl], p. 9.

${ }^{71}$ Ibíd.

${ }^{72}$ Ibíd., pp. 9-11.

${ }^{73}$ Op.cit. nota 40.
} 
ción de justicia protegen, como se verá, la afectación de estos presupuestos en contextos particulares. Pero pese a que ello sea una respuesta adecuada respecto al objeto de protección, no responde directamente a la pregunta por el fundamento de protección. Kindhäuser no responde a esta cuestión porque da por establecido el que el bien en cuestión se relaciona con el libre desarrollo de la personalidad. Esto es correcto, tal como se ha mostrado, pero el tipo de vínculo que establece entre libre desarrollo de la personalidad y administración de justicia resulta engañoso. En el ejemplo que utiliza al respecto, Kindhäuser intenta mostrar la forma en que afectaría al libre desarrollo de la personalidad el hecho que se presenten testimonios falsos o sentencias incorrectas, haciendo referencia a la falta de valor que tendría para un ciudadano presentar una demanda ante un tribunal en el que sabe se cometen falsos testimonios y prevaricaciones ${ }^{74}$. Aunque el ejemplo es elocuente, falla en el sentido que reconduce directamente al interés de individuos el fundamento de protección y, además, a través de una noción indirecta de confianza. Esto sin embargo no es necesario: la administración de justicia puede ser dañada en procesos respecto de los cuales los individuos normativamente no debieran tener interés -típicamente el derecho penal-. Además, en tanto bien de titularidad difusa completa, la afectación al libre desarrollo de la personalidad trasciende a los puros individuos que directamente se sirven o se pueden servir de la administración de justicia. En el ejemplo, no sólo resulta afectado este candidato a demandante y todos los que se encuentran en una situación como él, sino que si el incumplimiento general de las condiciones de funcionamiento de la administración de justicia hace que las demandas pasen a ser peligrosas -como asume el ejemplo-, ello tendría un efecto general en las formas de comportamiento recíprocas entre ciudadanos.

En el contexto español, Asua Batarrita identifica el objeto de protección de forma relativamente similar a lo que aquí se defiende. Aquí las bases metodológicas también son muy distintas. Lo que Asua pretende hacer es reconstruir el objeto de protección de los delitos contra la administración pública a partir de una explicación práctica del fenómeno criminológico de la corrupción $^{75}$. Pero al intentar conectar esta forma de análisis criminológico, cuyas pretensiones son político criminales, con un estudio de corte dogmático, Asua reconduce los delitos contra la administración pública a atentados

${ }^{74}$ Ibíd., p. 14.

${ }^{75}$ Asua Batarrita, Adela, La tutela penal del correcto funcionamiento de la Administración. Cuestiones politico-criminales, criterios de interpretación y delimitación respecto de la potestad disciplinaria, en Asua Batarrita, Adela (editora), Delitos contra la Administración Pública (Bilbao, Instituto Vasco de Administración Pública, 1997), pp. 13-14. 
contra condiciones posibilitadoras del ejercicio de derechos fundamentales ${ }^{76}$. Con ello pretende solucionar tanto los problemas que se suelen encontrar en la doctrina tradicional, a saber irreflexividad y falta de contenido, como los que se encuentran en la doctrina que reduce el concepto material de delito a pura infracción de deber, lo que si bien es sumamente verosímil, no tiene ningún potencial legitimador ${ }^{77}$. Así, reconociendo como principio esencial de la justificación material del delito el que se protejan intereses fundamentales de los ciudadanos, reconstruye los delitos en relación con expectativas de los ciudadanos relativos al ejercicio del poder estatal. "El funcionamiento correcto de la administración”, que en la práctica e institucionalmente se constituye para posibilitar el cumplimiento de esas expectativas, podría así ser visto correctamente como el bien jurídico protegido, lo que además contaría con apoyo institucional ${ }^{78}$. Asua se encuentra igualmente consciente que algo así como "el correcto funcionamiento de la administración" no puede ser identificado como "bien" de la misma forma que puede serlo, por ejemplo, la vida ${ }^{79}$. Por ello, recurre a los presupuestos que institucionalmente específica la Constitución, en un alto nivel de abstracción, para el correcto funcionamiento de la sociedad. Aquí el bien jurídico se constituye de forma puramente institucional, y además es un bien que cuando se afecta no se niega directamente, como en la lesión de bienes individuales, sino que simplemente deja de producirse. El bien jurídico sería, por lo tanto, una construcción normativa ${ }^{80}$.

Puede observarse que Asua reconstruye, de forma mucho más detallada, exactamente el modelo refinado de bien jurídico supra-individual que construyó Jakobs para luego refutarlo, detectando cada uno de los problemas que

${ }^{76}$ Ibíd. pp. 18-19.

${ }^{77}$ Ibíd. pp. 20-21.

${ }^{78}$ Ibíd. 22.

${ }^{79}$ No es, por cierto, sostenible que se trate, por un lado, de conceptos puramente normativos y, por el otro, de conceptos completamente dependientes de hechos brutos. Incluso en el bien jurídico que más parece depender de consideraciones naturales, la vida, influyen cuestiones normativas. Al respecto véase: Alcácer GuiraO, cit. (n. 37), p. 102-103. Por eso la distinción debiera ser entre conceptos regulados normativamente, como la vida, y conceptos constituidos normativamente, como la administración de justicia. Esta distinción, por cierto, está lejos de conducir a una distinción entre bienes jurídicos individuales y bienes jurídicos colectivos. Es conflictivo sostener que la propiedad, por ejemplo, sea una institución sólo regulada normativamente, aun cuando se intente hacerlo demostrando que la posesión es un hecho natural. Pues aunque esto último fuera cierto, no deja de ser igualmente cierta la necesidad natural de la sociedad de solucionar de alguna forma conflictos, con lo que un bien paradigmáticamente constituido normativamente tampoco lo sería en rigor. De ser admisibles estos argumentos, la distinción no tendría ningún sentido, ya que todo sería simplemente regulativo.

${ }^{80}$ Asua Batarrita, cit. (n. 75), pp. 23 ss. 
Jakobs le atribuye al modelo simple. Esto es un gran mérito del estudio de Asua. Sin embargo, la construcción de Asua tiene dos diferencias centrales con la concepción aquí defendida que no permiten que su criterio defina con suficiente precisión al bien jurídico en cuestión. El primero, es que agrupa todos los delitos contra la administración pública. Ello explica que no necesite en ningún momento distinguir cuál es el presupuesto específico de la sociedad moderna que se ve posibilitado por la administración de justicia: como agrupa casi todas las prestaciones estatales, hacer referencia a una prestación específica es imposible. En un trabajo más específico, como el que se pretende llevar acabo aquí, eso no es adecuado. Y además, se concentra exclusivamente en los delitos que son manifestaciones de deberes especiales, $\mathrm{o}$ que al menos inciden directamente sobre quienes tienen ese deber especial ${ }^{81}$. En cambio, hacerse cargo de la conexión de los distintos delitos comunes contra la administración de justicia con ésta, como bien jurídico, es una tarea importante en la construcción específica de este bien jurídico.

En Chile, y siguiendo de cerca la concepción defendida por Asua Batarrita, Luis Rodríguez Collao y María Magdalena Ossandón, también identifican el bien jurídico en cuestión en relación con el correcto funcionamiento de la administración pública / de Justicia ${ }^{82}$. Es así cómo lo que estaría detrás de la protección de la administración pública en general sería "su carácter instrumental en relación con la satisfacción de los intereses que justifican la existencia de la institución" ${ }^{83}$.

Es correcta la tesis que defienden Rodríguez Collao y Ossandón, en lo que sostienen que precisamente por ser un bien jurídico supra-individual, éste debe tener un carácter instrumental para intereses individuales que no sea identificable en cada caso en cuestión. Pero el paso de determinación del vínculo, al igual que Asua Batarrita, lo hacen a medias. Ello puede explicarse, tal vez, de la misma forma que en los otros. Las diferencias entre los intereses que podrían proteger la administración de justicia y la administración pública no permiten caracterizar con precisión esa relación instrumental. De hecho, Rodríguez Collao y Ossandón parecen reconocer esto al señalar que "aquél [el correcto funcionamiento de la administración pública] es un bien jurídico de naturaleza institucional o supra-individual, que se estructura sobre la base de caracteres esencialmente normativos, que varían

${ }^{81}$ Ibíd. p. 23. Asua explica de esta forma los delitos que son cometidos "desde fuera" y que son manifestación de corrupción. Es evidente, por lo demás, que se concentra sólo en éstos y no en delitos que no pretenden influir directamente sobre quienes tienen deberes especiales, porque estos últimos, no son formas paradigmáticas de corrupción, por lo que exceden el área de interés del estudio de Asua.

${ }^{82}$ Rodríguez Collao - Ossandon Widow, cit. (n. 45), pp. 98 a 100.

${ }^{83}$ Ibíd. p. 99. 
ostensiblemente de un delito a otro. De ahí la necesidad de precisar, frente a

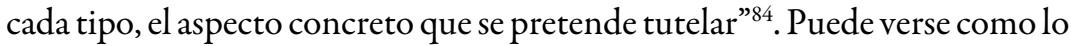
que hacen es desplazar la concepción crítica que puede tener el bien jurídico a la discusión acerca de cada tipo, o sub-clase de tipos. Ello puede parecer sensato, y de hecho es importante explicar la conexión con el bien jurídico de cada delito de la clase. Pero renunciar a precisar en forma absolutamente mínima el contenido general del bien jurídico, en condiciones que se asume una distinción básica entre administración pública y administración de justicia, es contra-producente si se pretende construir un bien jurídico con una función crítica y sistemática. De hecho el grado de imprecisión al que llegan puede verse con claridad, al mostrar qué intereses específicos, a modo de ejemplo, podrían estar en juego: "decisión conforme a legalidad; actuación conforme a un fin determinado; observancia de la objetividad; preservación de la imparcialidad; coordinación jerárquica en aras de la eficacia; actuación conforme a garantías procedimentales, etc." ${ }^{85}$. Es decir, cualquier cosa específica que pueda tener un mínimo interés instrumental, aún aparente, para la protección o posibilitación de bienes jurídicos individuales. Pese a que en algún sentido intenten corregir ese defecto cuando tratan en particular la administración de justicia, identificándola como "función" y no como "órgano", nuevamente esconden la conexión funcional entre la administración de justicia e intereses individuales ${ }^{86}$, sólo recalcando su "especificidad" frente a la función de la administración pública en general ${ }^{87}$. Pero, precisamente, eso no es lo relevante al asignarle contenido.

Todas las teorías recién expuestas son similares en lo esencial con la construcción aquí entregada, pese a tener enfoques distintos y a no entregar una fundamentación de la necesidad de protección de las condiciones de ejercicio de la función, como condición de posibilidad, a su vez, de la libertad general de acción.

c) La estructura de peligro abstracto de los bienes contra la administración de justicia y titularidad difusa. El bien jurídico administración de justicia se encuentra estructurado de forma tal que no es complejo reconocer en éste un bien jurídico colectivo, esto es, de titularidad

${ }^{84}$ Ibíd.

${ }^{85}$ Ibíd.

${ }^{86}$ En todo, Ibíd. pp. 151 ss. Es un tanto extraño el tratamiento que hacen, ya que lo que analizan es el "concepto" de administración de justicia. Ello no tiene ningún vínculo explícito con categoría penal alguna, pero pareciera ser una discusión específica entorno a lo que ellos denominan la conexión instrumental, o la función específica que se protege.

${ }^{87}$ Ibíd. p. 155 
difusa, y respecto del cual sus tipos tienden a configurarse como delitos de peligro abstracto.

No es difícil advertir que la administración de justicia es un bien jurídico colectivo. Aunque en algunos de sus supuestos puede resultar afectado un particular -por ejemplo, indirectamente, en caso que testigo declara falsamente contra él o, directamente, en un caso de prevaricación contra sus intereses-, esa incidencia particular sobre derechos de titularidad de un particular es irrelevante. Ello implica que en el caso de delitos contra la administración de justicia no procede el consentimiento - no hay titular de bien jurídico que pueda disponer de él-, ni procede la legítima defensa. La estructura del objeto de protección excluye ambas cosas.

En lo segundo, tampoco es difícil advertir el hecho que la regulación positiva de los delitos contra la administración de justicia adopta estructuras de peligro abstracto. Ello sucede de forma clara con el falso testimonio: no sólo se trata de un delito de mera actividad, sino que a diferencia, por ejemplo, del recurso de revisión, no se exige influencia en la sentencia por parte del testimonio falso. Aun cuando el juez pueda advertir la falsedad y evitar la influencia de éste en su sentencia, la conducta es punible y con independencia que haya hecho probable una incidencia de este tipo. Distinto es el caso de la prevaricación. Pese a tratarse de un delito de mera actividad, ésta tiene que manifestarse en una sentencia y por lo tanto en la no producción del bien en cuestión en concreto (pese a que puede ser subsanado por la procedencia de recursos). Aunque la estructura de bien jurídico colectivo hace compleja la aplicación de la distinción entre delitos de lesión y delitos de peligro -ya que para su aplicación simple éstos requieren el reconocimiento de un objeto de ataque y de condiciones de lesión de éste, todo lo cual requiere de un titular del objeto de ataque-, su estructura es ciertamente distinta a un caso en que claramente concurre la calidad de peligro abstracto, como en el caso del falso testimonio. La regulación de los delitos de imputación falsa y de obstrucción a la justicia también tiende a tener la misma configuración.

Esto no debiera ser llamativo. En tanto bien con configuración puramente normativa y cuya producción requiere cumplimiento general de ciertos presupuestos -sujeción al derecho, imparcialidad, independencia, fiabilidad cognitiva en el proceso-, la forma adecuada de protección del objeto es la protección de sus presupuestos, con independencia de que ello afecte o no la posibilidad de producción concreta de una resolución adecuada en un caso determinado. Con eso, la estructura de peligro no sólo se encuentra justificada, sino que es necesaria a esta categoría ${ }^{88}$.

${ }^{88}$ En el mismo sentido KINDHÄUSER, cit. (n. 40), pp. 15 a 18, quien explica que en un bien con las características de la administración de justicia, la afectación de presu- 
d) Formas de afectación a la administración de justicia como condición de posibilidad. Los delitos contra la administración de justicia afectan presupuestos de su funcionamiento. Es decir, en tanto condición de posibilidad de la libertad, ésta se ve afectada cuando las condiciones de su condición son perturbadas.

Las formas en que puede afectarse esta condición de posibilidad admiten dos criterios de clasificación muy simples. La primera atiende al presupuesto específico que se lesiona, y por ello cobra importancia la segunda digresión sobre los presupuestos mínimos de la administración de justicia. En los casos de corrupción, por ejemplo, el presupuesto que se afecta es la imparcialidad o la independencia (y con ello mediatamente o incluso como peligro abstracto, a la sujeción al derecho). Pero aún en el caso de delitos funcionarios, la afectación no se relaciona necesariamente con la corrupción, por lo que la afectación no se relaciona directamente con la imparcialidad e independencia, como hacen suponer todos los estudios que como Kindhäuser y Asua parten desde el fenómeno de la corrupción. La prevaricación judicial, por ejemplo, resulta directamente en una afectación a la legalidad como presupuesto de la administración de justicia, y sólo de forma contingente e indirecta a la imparcialidad o la independencia. La corrupción no es un presupuesto necesario, en ningún caso, de la consumación de este tipo. En el caso de los delitos de particulares, éstos afectan presupuestos específicos de la administración de justicia que se configuran como contextos de protección especial -proceso e investigación penal- sobre los que se volverá más adelante.

La segunda forma de clasificación, tal vez más relevante que la primera, atiende a la persona, configurada en relación con roles identificables normativamente, que afecta esta posibilidad. Los delitos contra la administración de justicia pueden ser realizados por quienes tienen el deber específico de producir esa condición de posibilidad, de producir la estabilización de expectativas normativas a través del ejercicio de la jurisdicción, o por quienes no tienen ese deber específico pero que igualmente se encuentran obligados a prestar una solidaridad mínima con esa posibilidad. Prácticamente todos los estudios sobre este tipo de delitos recogen, de alguna u otra forma, esta distinción, ya que es central para el tratamiento correcto de la mayoría de los problemas de imputación que pueden producirse en éstos. Por ello, por lo central que resulta la distinción, nos referiremos de forma más extendida al tema.

\section{Afectaciones a la administración de justicia infringiendo un deber es-}

puestos de su funcionamiento implica ya una pérdida de su valor, esto es, de la eficacia de la prestación que entrega a la sociedad. 
pecifico y afectaciones infringiendo deberes generales justificados en contextos especiales.

De la existencia de un bien que requiere de una prestación positiva de parte de la sociedad para existir, no se deduce inmediatamente la existencia de un reforzamiento penal de los deberes positivos vinculados a su producción, aunque sí se trata de un antecedente relevante que, de justificarse la importancia del bien, puede llevar a la construcción de la justificación del reforzamiento penal. La imposición de deberes positivos o negativos ligados a la producción del bien en cuestión por parte de quienes no tienen la obligación directa de contribuir a su creación no cuenta, en cambio, con esa justificación a priori.

En el primer caso, el deber del autor es un deber que se configura no en relación con la persona como simple sujeto que debe cumplir con ser fiel al derecho mediante la no arrogación de libertades ajenas, sino que se configura a la persona en relación con la adopción de un rol de características especiales ${ }^{89}$. Su fidelidad al derecho no es mera fidelidad pasiva, sino que se le exigen determinadas prestaciones activas, cuya justificación coincide parcialmente con la construcción de su personalidad desde el punto de vista de la comunidad. Tratándose de los delitos contra la Administración de justicia, la posición del juez frente al Derecho justifica directamente, como un deber especial que forma parte de su rol de juez, la obligación activa de producir el derecho y, por lo tanto, la obligación pasiva de no declarar como derecho algo que no constituye derecho. En su caso, la legitimación de la normas de comportamiento que subyacen a los delitos de los que es sujeto especial no tiene dificultades de producción.

No sucede lo mismo cuando se imputa falta de fidelidad al derecho a una persona en su rol de persona o de ciudadano común. La justificación de la obligación y del reforzamiento penal no arranca de la consideración de su rol, respecto del cual se espera únicamente que cumpla con deberes negativos generales. Los deberes negativos generales de la persona se constituyen a partir del otorgamiento de derechos de exclusión relativos a la propiedad, entendida como propiedad sobre el cuerpo y sobre cosas. En este sentido "la propiedad (es) una relación negativa, un derecho a no ser perturbado por los demás" ${ }^{\prime 0}$ dentro del ámbito de lo que se tiene. De esta relación de mutua exclusión entre personas, se deduce el derecho de no perturbar la organización de derechos de terceros, y de organizarse, a la vez, de forma que la organización de uno no lleve a resultados lesivos. No se deducen, en

${ }^{89}$ Jаковs, Günther, La idea de la normativización en la dogmática jurídico-penal, en del mismo Sobre la normativización de la dogmática penal (Madrid, Civitas, 2003), p. 23.

${ }^{90}$ Ibíd. p. 28. 
cambio, de la configuración de la persona, inmediatamente deberes positivos, ni menos deberes positivos reforzados penalmente.

La justificación de los deberes positivos de personas en su rol de personas, requiere de argumentos que justifiquen la construcción de un contexto especial de imposición de deberes activos ${ }^{91}$. Lo mismo sucede con los deberes negativos que no se relacionan con la consideración inicial de los derechos de exclusión que emanan directamente de la personalidad y propiedad como protección general. Fuera de los contextos especiales que el derecho puede construir, no le es exigible penalmente a la persona una solidaridad activa con el otro, ni una solidaridad pasiva con sujetos indeterminados que no afecte directamente a la personalidad y propiedad de otro. En el caso de la estabilización de expectativas normativas mediante la resolución de conflictos, la que precisamente entra en esta segunda categoría de bienes, dos son los contextos especiales en que la sociedad impone obligaciones generales de solidaridad pasiva con este bien.

El primer contexto en que se le imponen obligaciones especiales a la persona de solidaridad pasiva fuera del ámbito de exclusión de la personalidad individual de otro, es el contexto especial de la persecución penal. La persecución penal es la manifestación del interés de la sociedad de expresar comunicativamente reproche a otro por la lesión de bienes esenciales, el que tiene una calidad expresiva suficiente para contrarrestar y superar la negación de esos bienes. La sociedad no les exige a todos colaborar activamente con la creación de este bien, o al menos no refuerza ese deber con penas en Chile, más allá de los casos excepcionales de denuncia obligatoria. Pero sí lo hace respecto de la obligación de no perturbar la persecución penal estatal, por su importancia central en la estabilización de las expectativas más relevante y, eventualmente, más frágiles. La persecución e investigación penal constituye un contexto de imposición de deberes solidarios pasivos especiales.

El segundo contexto especial que justifica la imposición de obligaciones especiales a la persona es el proceso. La estabilización de expectativas normativas no tendría efectos relevantes si fuera ciega, esto es, si actuara sin base cognitiva al resolver conflictos. Y, sin embargo, se le impone a la función judicial la carga de reconstruir la base cognitiva de sus resoluciones normativas en un contexto de relativa ceguera. Esto es, la función de los jueces se configura siempre en relación con conflictos ya acaecidos a partir

${ }^{91}$ La justificación de deberes particulares en ámbitos de deberes institucionales por parte de Jakobs toma un rumbo distinto al señalado aquí. En su opinión, para que el deber institucional pueda realizarse, se le exige al particular no molestar a quien tiene deberes especiales en el cumplimiento de éstos, lo que en ámbitos particularmente relevantes podría justificar penas. Al respecto, véase: JАKOBs, Günther, cit. (n. 6), pp. 7 a 14. 
de hechos pasados que son casi siempre imposibles de ser percibidos por el juez. La reconstrucción de los hechos sin poder verificar de modo directo esos hechos requiere, por lo tanto, de una base estabilizadora de la veracidad de lo que se reconstruye. Esa base la entrega el proceso, el que por definición tiene que exigir a quienes participan de la reconstrucción fáctica de los hechos pasados, que sus comunicaciones no sean, al menos, sabidamente falsas. De esta forma, la sociedad le exige a la persona no afectar a este contexto especial de modo deliberado, y esto lo refuerza penalmente ${ }^{92}$. Ese especial deber de sinceridad se justifica, por lo tanto, en la fragilidad del contexto de estabilización de expectativas.

\section{BIBLIOGRAFÍA}

Alcacer Guirao, Rafael, Sobre el concepto de delito. ¿Lesión del bien jurídico o lesión de deber? (Buenos Aires, Ad Hoc, 2003).

Asua BATARrita, Adela, La tutela penal del correcto funcionamiento de la Administración. Cuestiones político-criminales, criterios de interpretación y delimitación respecto de lapotestad disciplinaria, en Asua Bat arrita, A. (editora), Delitos contra la Administración Pública (Bilbao, Instituto Vasco de Administración Pública, 1997).

BASCUÑáN RodRÍGUEz, Antonio, Comentario critico a la regulación de los delitos contra el medio ambiente en el Anteproyecto de Código Penal de 2005, en Estudios Públicos. Revista de Humanidades y Ciencias Sociales, 110 (Santiago, 2008).

BASCUÑán Rodríguez, Antonio, La regulación española de la coerción en el marco de la codificación europea (Madrid, ADPCP, 1994).

Beccaria, Cesar, De los delitosy laspenas (México D.F., Fondo de Cultura Económica, 2000).

Carrara, Francesco, Programa de Derecho criminal (Bogotá, Editorial Temis, 1958).

Donna, Edgardo Alberto, Derechopenal. Parte especial (Buenos Aires, Rubinzal-Culzoni Editores, 1999).

${ }^{92}$ La distinción central reseñada, con algo más de precisión, no es muy distinta a las clasificaciones usuales en la doctrina nacional de los delitos contra la administración de justicia. Matus - Politoff - Ramírez, cit. (n. 55), distinguen entre delitos cometidos por funcionarios públicos y delitos cometidos por particulares. Pese a que la clasificación hecha en esos términos tiene algún sentido, desatiende al hecho que, muchas veces, el tipo común es a la vez un tipo especial impropio contra la administración de justicia. Por otro lado, Ossandón Widow - Rodríguez Collao, cit. (n. 45), pp. 172 ss., con mayor precisión distinguen entre delitos contra la administración de justicia por infracción de deberes especial y por "dominio". Sin embargo, al aplicar esta clasificación, llegan a conclusiones distintas, señalando por ejemplo que el deber del testigo es un deber institucional, pp. 242 ss. , en condiciones que la obligación del testigo de declarar la verdad no es una obligación auto-impuesta en ningún sentido. Esta distinción central reseñada debiera ser complementada, además, con la distinción tradicional entre delitos que afectan a la confianza y delitos que afectan recursos. 
Dworkin, Ronald, Law's Empire (Harvard, Belknap, 1986).

Ferrajoli, Luigi, Derecho y razón: Teoría del garantismo penal (Madrid, Trotta, 2001)

García de Enterría, Eduardo, La Democracia y el lugar de la Ley (Civitas, Madrid, s.d.).

Garrido Montt, Mario, Derecho penal. Parte especial (Santiago, Editorial Jurídica de Chile, 2000).

GüNTher, Klaus, De la vulneración de un derecho a la infracción de un deber. ¿Un cambio de paradigma en el Derecho penal?, en Instituto de Ciencias Criminales de Frankfurt - Área de Derecho penal de la Universidad Pompeu Fabre, La insostenible situación del derecho penal (Granada, Editorial Comares, 2000).

Habermas, Jürgen, Aspectos de la racionalidad de la acción, en El mismo, Teoría de la acción comunicativa: complementos y estudios previos (Madrid, Cátedra, 2001).

Habermas, Jürgen, Facticidad y validez (4a edición, Madrid, Trotta, 2005).

Hart, H.L.A., El concepto del Derecho (Buenos Aires, Abeledo Perrot, 1977).

Hassemer, Winfried, Derecho penal y Filosofía del Derecho en la República Federal de Alemania, en El Mismo, Persona, mundo y responsabilidad: bases para una teoria de la imputación en el derecho penal (Santa Fe de Bogotá, Temis, 1999).

Hegel, G.W.F., Principios de la Filosofía del Derecho (Buenos Aires, Editorial Sudamericana, 2004).

Jаков , Günther, ¿Quéprotege el Derecho penal, bienes jurídicos o la vigencia de la norma? (Ediciones Jurídicas Cuyo, Mendoza, 2001).

Jаковs, Günther, Consumación material en los delitos de lesión contra la persona, en Revista Electrónica de Ciencia Penal y Criminología, 04-13 [http://www.criminet. ugr.es/recpc, 2002].

JAKOBS, Günther, La idea de la normativización en la dogmática jurídico-penal, en EL MISMO, Sobre la normativización de la dogmática penal (Civitas, Madrid, 2003).

JАKовS, Günther, Lapena estatal: significado y finalidad, en EL MISMO, El fundamento del sistema jurídico penal (Lima, ARA Editores, 2005).

KAHLO, Michael, Sobre la relación entre el concepto de bien jurídico y la imputación objetiva en el derecho penal, en HEFENDEHL y otros, La teoría del bien jurídico. ¿Fundamento de legitimación del derecho penal o juego de abalorios dogmático? (Madrid, Marcial Pons, 2007).

Kant, Immanuel, La metafisica de las costumbres (Madrid, Tecnos, 2002).

Kelsen, Hans, Teoría Pura del Derecho (Universidad Nacional Autónoma de México, México D.F., 1979).

KIndhäUser, Urs, Presupuestos de la corrupión punible en el Estado, la Economía y la Sociedad. Los delitos de corrupción en el Código Penal alemán, en Política Criminal, 3, A1 [http://www.politicacriminal.cl], 2007).

Lagodny, Otto, El derecho penal sustantivo como piedra de toque de la dogmática constitucional, en HEFENDEHL y otros, La teoría del bien jurídico. ¿Fundamento de legitimación del derecho penal o juego de abalorios dogmático? (Madrid, Marcial Pons, 2007).

Luhmann, Niklas, Sistemas sociales, lineamientos para una teoría general (México D.F., Anthropos, 1998).

Mañalich, Juan Pablo, Lapena como retribución, en Estudios Públicos, 108 (Santiago, primavera 2007). 
Matus, Jean Pierre - Politoff, Sergio - Ramírez, María Cecilia, Lecciones de Derecho penal chileno (Santiago, Editorial Jurídica de Chile, 2003).

Montesquieu, De l'esprit des lois (Paris, Gallimard, 1995).

Muñoz Conde, Francisco, Derecho penal. Parte especial (Tirant Lo Blanch, Valencia, 2004).

Müssig, Bernd, Desmaterialización del bien jurídico y de la politica criminal. Sobre las perspectivas y los fundamentos de una teoría del bien jurídico, crítica hacia el sistema (Bogotá, Universidad Externado de Colombia, 2001).

Peñaranda Ramos, Enrique - Suárez González, Carlos - Cancio Meliá, Manuel, "Prólogo" a Estudios de Derecho penal (Madrid, Civitas, 1997).

Rawls, John, Dos conceptos de reglas, en Teorías sobre la Ética (edición a cargo de Philippa Foot, México D.F, Fondo de Cultura Económica, 1974).

Rodríguez Collao, Luis - Ossandón Widow, María Magdalena, Los delitos contra la función pública (Santiago, Editorial Jurídica de Chile, 2005).

Rousseau, Jean Jacques, El Contrato social y otras obras (Buenos Aires, Losada, 2003).

Roxin, Claus, ¿Qué puede reprimir penalmente el Estado? Acerca de la legitimación de las conminaciones penales, en del mismo Problemas Actuales de Dogmática Penal (Lima, ARA Editores, 2004).

Roxin, Claus, Derecho penal Parte General, Tomo I, Fundamentos y Estructura de la Teoría del Delito (Madrid, Civitas, 1997).

Roxin, Claus, Sentido y límites de la pena estatal, en del mismo Problemas básicos del derecho penal (Madrid, Reus, 1976).

Schmitt, Carl, Legalidad y Legitimidad (Colección Crítica del Derecho (Granada, Comares, 2006).

SCHÜNEMANN, Bernd, Elprincipio deprotección de bienes juridicos comopunto de fuga de los limites constitucionales de los tipos penales y de su interpretación, en HEFENDEHL y otros, La teoría del bien jurídico. ¿Fundamento de legitimación del derecho penal o juego de abalorios dogmático? (Marcial Pons, Madrid, 2007).

Silva Sánchez, Jesús María, Aproximación al Derecho penal Contemporáneo (Barcelona, Bosch, 1992).

Silva Sánchez, Jesús María, La expansión del Derecho penal: aspectos de la politica criminal en las sociedades postindustriales (Madrid, Civitas, 2001).

Tittmann, Karl August, Contribuciones a la doctrina de los delitos contra la libertad (Meißen, s.l., 1806) (traducción de Bascuñán Rodríguez, Antonio).

Weber, Max, Economia y sociedad (México D.F., Fondo de Cultura Económica, Segunda Edición, 1969).

Weber, Max, La ética protestante y el espiritu del capitalismo, en del mismo Obras Selectas (Buenos Aires, Distal, 2003). 
